\title{
The short term prediction of analysts' forecast error
}

\author{
Kris Boudt \\ Peter de Goeij \\ James Thewissen \\ Geert Van Campenhout
}
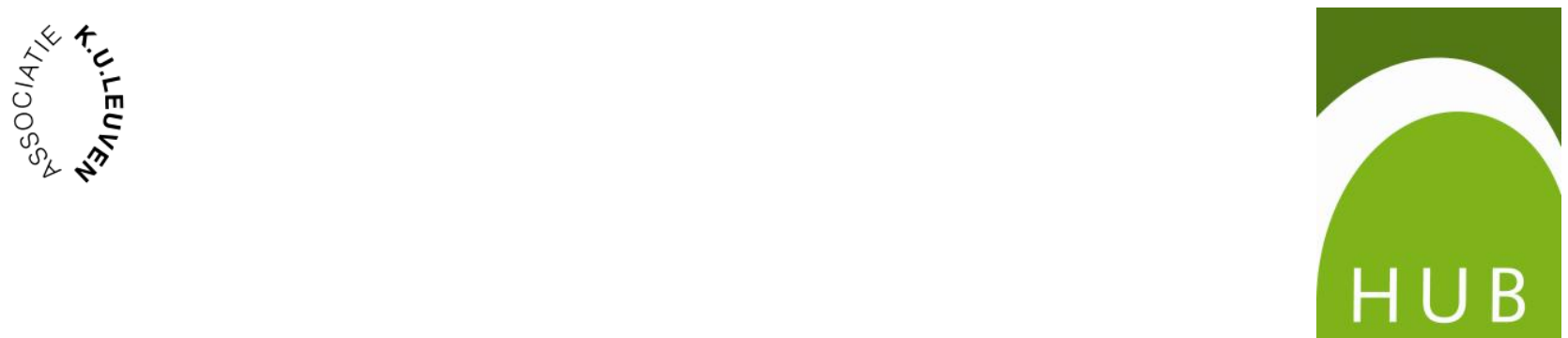


\title{
The short term prediction of analysts' forecast error ${ }^{\text {tis }}$
}

\author{
Kris Boudt $^{\mathrm{a}, \mathrm{b}, \mathrm{c}}$, Peter de Goeij ${ }^{\mathrm{d}}$, James Thewissen ${ }^{\mathrm{a}, \mathrm{b}, \mathrm{e}}$, Geert Van Campenhout ${ }^{\mathrm{a}, \mathrm{e}}$ \\ ${ }^{a}$ Faculty of Business and Economics, K.U.Leuven, Belgium \\ ${ }^{b}$ Department of Business Studies, Lessius University College, Belgium \\ ${ }^{c}$ Faculty of Economics and Business, V.U.University of Amsterdam \\ ${ }^{d}$ Tilburg Law and Economics Center (TILEC), Tilburg University, The Netherlands \\ ${ }^{e}$ Department of Economics \& Management, FAcT Research Group, HUBrussel, Belgium
}

\begin{abstract}
We examine the profitability of implementing a short term trading strategy based on predicting the error in analysts' earnings per share forecasts using publicly available information. In the 1998-2010 I/B/E/S data, the strategy of taking a long (short) position in stocks with the most pessimistic (optimistic) consensus forecast and closing the position on the first post announcement day has an annual gross abnormal return of $16.56 \%$, after correcting for market risk, size, book-to-market and price momentum effects. A key insight is that the profitability of the trading strategy stems from using robust forecasting methods and from focusing on the stocks with the most extreme predicted forecast errors. The trading strategies using least squares regression and/or focusing merely on the sign of the forecast error are not profitable.
\end{abstract}

Keywords: Financial analysts, Forecast error, Short term prediction, Trading strategy

\section{Introduction}

In this paper we study the predictability of analysts' forecast error and examine the profitability of a short term trading strategy conditional on the sign or the magnitude of this predicted forecast error.

There exists a significant body of accounting and finance literature on the earnings announcement effect and subsequent post-earnings drift. Abarbanell and Bernard (1992) were among the first to show that pessimistic (optimistic) analysts' forecasts result in positive (negative) long term cumulative returns. In the wake of this lit-

\footnotetext{
"Part of the research was carried out thanks to financial support in the form of a grant from the Dutch Science Foundation, the Intercollegiate Center for Management Science and the National Bank of Belgium. We thank Jean-Yves Gnabo and Stephen Young for their valuable comments.
} 
erature, research has also investigated the predictability of analysts' forecasts and has looked at the implications for the market efficiency hypothesis by developing trading strategies using the predicted forecast error as a signal. A common feature of this literature (summarized in the Appendix) is to focus on a long term investment horizon (i.e. one month horizon or longer). Although a long term investment horizon might be sensible in view of the documented length of the post-earnings announcement drift, it also entails substantial risk for the implementation of any trading strategy. It is clear that a short term trading horizon could substantially limit the trading strategy risk. In addition, little to no attention is devoted to the impact of outliers on the prediction of forecast errors, although it is well known that outliers can significantly affect predicted values (see e.g. Ledoter, 1989; Hotta, 1993).

We aim at filling this gap by focusing on the short term profitability (given realistic levels of transaction costs) of two trading strategies that rely on the sign or the magnitude of the predicted forecast error one week before the earnings announcement date. An important contribution of this paper is that we demonstrate that robust estimation techniques significantly improve the prediction of the forecast error, while the traditional OLS procedure yields a poor out-of-sample prediction performance. Moreover, the robust estimation procedure is essential for the profitability of the trading strategy.

In our forecast error prediction model we combine two categories of variables. The first set of variables is related to analysts' earnings forecasts (see e.g. Ali et al., 1992; Mendenhall, 1991; Abarbanell and Bernard, 1992). The second category draws upon research that uses prior stock performance variables related to analysts' forecast error (see e.g. Elgers and Lo, 1994). Since extreme values in analysts' forecast error could have an influential impact on the actual forecast, we use a robust linear panel-data model with a continuous dependent variable capturing both the sign and the magnitude of analysts' forecast error. We then analyze the profitability of two short term trading strategies that exploit the sign and magnitude of the predicted 
error in analysts' consensus forecasts. In the Sign strategy, we take a long (short) position in firms for which the predicted forecast error is negative (positive). In the Magnitude strategy, we classify firms based on the sign and magnitude of the predicted forecast error and initiate a long (short) position in the firms included in the first (last) decile.

Over the 1998-2010 period, the Magnitude strategy yields significant profits with an annual gross abnormal return of $16.560 \%$ over a 7 -day trading horizon, starting 5 trading days before the earnings announcement. Trading strategies that rely only on the sign of the predicted forecast error, and/or use OLS instead of robust estimation techniques, do not yield significant abnormal returns.

The remainder of the paper is organized as follows. In Section 2, we discuss the variables used in our predicion model. In Section 3, we describe our data sample and summary statistics. In Section 4, we introduce the forecast methodology and study the prediction performance. The Sign and Magnitude trading strategies and their profitability are discussed in Section 5. Finally, Section 6 concludes.

\section{Selection of prediction variables}

Our prediction model aims at predicting the consensus analysts' forecast error based on a information set of which all variables are publicly observable at the moment we initiate our trading strategy (i.e. 5 trading days prior to the earnings announcement). Analysts' forecast error $\left(f e_{j, t}\right)$ is defined as the difference between analysts' consensus forecast and the actual earnings, scaled by the closing price on the day before the forecast date. A positive (negative) forecast error thus points to an optimistic (pessimistic) consensus.

We combine insights from two streams of research to construct our prediction model. The first stream exploits analysts' forecast variables. For instance, in view of the results in Abarbanell and Bernard (1992) and Mendenhall (1991) that analysts underestimate the persistence of past earnings forecast errors, earnings forecast accuracy can be improved significantly by adjusting current forecasts for this serial 
dependency (Ali et al., 1992). In addition, we also include analysts' coverage and forecast dispersion as analysts' forecast variables. A second stream of research considered variables related to prior stock performance to predict analysts' forecast error. For example, Elgers and Lo (1994) examine the association between analysts' earnings forecast errors and prior stock returns and show that analysts' error can be predicted more accurately by accounting for prior return information. We further include earnings-to-price ratio and firm size as predictors, together with two control variables (i.e. a dummy variable for forecasts made for fourth quarter earnings and a regulatory dummy related to the Regulation Fair Disclosure). The definition of the variables, together with their expected sign, are summarized in Table 1.

\subsection{Analysts' forecast variables}

The first group of variables is derived directly from analysts' forecasts. The lagged forecast error is related to the documented positive autocorrelation in analysts' forecast error time series (Abarbanell and Bernard, 1992; Mendenhall, 1991; Ali et al., 1992). Because the relation of analysts' forecast error and lagged forecast error is different for positive and negative lagged forecast error (see supra, Table $3)$, we include positive (Pos. $\left.f e_{j, t-1}\right)$ and negative forecast error $\left(N e g . f e_{j, t-1}\right)$ separately. Das et al. (1998) show that analysts become more optimistic the more uncertain the information environment. We therefore include dispersion in earnings forecasts $\left(D i s p_{j, t}\right)$ as a proxy for information uncertainty. Finally, including analyst coverage should increase the predictability of the model. Analyst coverage $\left(\operatorname{Cov}_{j, t}\right)$, measured as the logarithm of the number of analysts, is likely to be negatively correlated with the information uncertainty of a firm, so we would expect forecast optimism to be lower, the higher analyst coverage. Furthermore, Bhushan (1989) shows that coverage is positively related to firm size, corroborating the negative relation mentioned above. Nevertheless, analyst coverage is also likely to be related to analysts' forecasting behavior. As indicated by $\mathrm{Gu}$ and $\mathrm{Wu}$ (2003), more intense competition between analysts may cause more optimistic forecasts because analysts 
use it as a means to facilitate access to information. We therefore have no a priori expectations about the sign of the impact of coverage on forecast error.

\subsection{Prior stock performance}

The second category consists of variables related to prior stock performance. Elgers and Lo (1994) found that prior security returns are associated with analysts' forecast error. Using size-adjusted cumulative returns, they show that optimistic bias in analysts' forecasts is likely to be greater for firms having poor prior-period earnings performance. They argue that analysts have incentives to provide optimistic earnings forecasts to maintain good relations with management (see also Francis and Philbrick, 1993). Following Jegadeesh et al. (2004), we have two measures for cumulative market-adjusted return: $P 1 R^{2} t_{j, t}$ which measures the cumulative market-adjusted return for the two quarters preceding the quarter under investigation, and $P 2 R_{e} t_{j, t}$ which is the same measure for quarter -4 to quarter -2 . Furthermore, we include firm size $\left(S_{i z e_{j, t}}\right)$. Dichev and Tang (2009) show that firms with low earnings volatility have high earnings predictability and that analysts are more optimistic for firms with low earnings predictability. Since information uncertainty decreases with firm size, we expect firm size to be negatively correlated with forecast error. This effect might be even more pronounced if analysts issue optimistic forecasts in order to facilitate communication with the firm's management ( $\mathrm{Gu}$ and $\mathrm{Wu}, 2003)$. In line with Bhushan (1989), we measure size by the logarithm of a firm's market value. Finally, we add to the literature by including the lagged earnings-to-price ratio $E P_{j, t-1}$ as a prediction variable. A high (low) earnings-toprice ratio points to value (growth) stocks, which are characterized by low (high) earnings volatility. In line with Dichev and Tang (2009), we therefore posit that the earnings-to-price ratio should be negatively related to analysts' optimism. 


\subsection{Control variables}

We also add a number of control variables related to the earnings announcement in the fourth quarter and the Fair Disclosure Regulation. Analysts' forecasts for fourth quarter $\left(Q 4_{t}\right)$ earnings might differ systematically from forecasts for earnings in the other quarters because, unlike in the case of interim earnings, negative extraordinary items and losses are more prevalent in the reporting of the fourth quarter (Basu et al., 1999; Beaver et al., 2008). Given the unpredictable nature of extraordinary items and losses, we expect analysts' forecasts to be more optimistic for the fourth quarter, relative to other quarters. We include a dummy variable that permits the fourth-quarter slope coefficients to differ from those of the interim quarters. With respect to legislation, analysts' behavior has been significantly influenced by the introduction of the Regulation Fair Disclosure $\left(\operatorname{Reg} F D_{t}\right)$ in the fall of 2000. This regulation requires managers to disclose material non-public information to all market participants at the same time. By prohibiting the selective disclosure of material information to financial professionals, such as financial analysts, the latter should no longer have an incentive to issue optimistic forecasts in order to gain access to privileged company information. We thus expect analysts' consensus forecasts to be more pessimistic after the enforcement of the Regulation.

Insert Table 1 about here.

\section{Data description}

\subsection{Sample}

Analysts' quarterly earnings forecasts and actual earnings in the period 19952010 are obtained from the Institutional Broker Estimate System (I/B/E/S) database. Our sample consists of U.S. companies with fiscal year end in December and is restricted to firms with a minimum share price of at least $\$ 3$ to avoid the small deflator 
problem (Gu and $\mathrm{Wu}, 2003)$. Because we initiate our trading strategy 5 trading days before the earnings announcement, only the most recent forecast per analyst that is observable at that time is considered. We focus on the profitability of trading strategies involving the consensus of analysts' earnings forecasts. The consensus is a natural choice, as it takes into account the public and private information implicit in the forecasts of all the analysts following a particular stock. It is arguably the analyst statistic that is most easily accessed by investors.

To mitigate errors in the earnings announcement date, we require the reported date to be identical in the I/B/E/S and COMPUSTAT databases. Furthermore, we only keep the quarterly earnings announcement if the report date does not exceed the SEC filing deadline, set at 45 days following the end of the quarter. Forecast errors in excess of $100 \%$ are also excluded because it is most likely that these result from a data input error. Stock prices, returns and market capitalization data are taken from CRSP. Our final sample consists of 57,213 analysts' quarterly consensus forecasts from 3,400 firms.

\subsection{Descriptive statistics - Portfolio characteristics and stock returns}

A necessary condition of developing trading strategies based on analysts' forecast error is to establish whether analysts' forecast error is a trustworthy signal for implementing trading strategies. Table 2 provides descriptive statistics for portfolios formed on the basis of analysts' forecast error. Firms are assigned to deciles, with decile 1 and decile 10 consisting of firms with the most negative and positive forecast error, respectively. The results reveal the well known negative relation between analysts' forecast error and stock returns as we move from highly pessimistic to highly optimistic forecasts. The mean three-day cumulative abnormal return around the earnings announcement day $(\mathrm{CAR}[-1 ;+1])$ equals $3.822 \%$ for the extreme negative forecast error decile (decile 1) and $-4.644 \%$ for the extreme positive forecast error 
decile (decile 10), both significant at a $99 \%$ level. ${ }^{1}$ This pattern of decreasing forecast error and stock returns points to a monotonic negative relation between analysts' forecast optimism and abnormal returns. This is confirmed by the Patton and Timmerman (2010) procedure that tests the null hypothesis of equal or weakly increasing abnormal returns over forecast error deciles against the alternative hypothesis of a monotonically decreasing relation. Using a bootstrap replication of 1,000 portfolios, we find a p-value less than 0.001. This pattern of decreasing stock returns is pictured in Figure 1, which plots the interquartile range and median $\mathrm{CAR}[-1 ;+1]$. Untabulated results indicate that analysts' forecast error is significantly correlated with the cumulated abnormal return around the earnings announcement date, with a correlation of $-7.593 \%$.

The monotonic negative relation between analysts' error and stock returns implies that a pessimistic (optimistic) consensus forecast leads, on average, to a positive (negative) stock price reaction around the earnings announcement day. However, looking at the frequency of positive (negative) stock price reactions to a pessimistic (optimistic) consensus forecast yields different insights into this relation. Indeed, many firms' forecast error and returns do have the same sign. As shown in column (6) of Table 2, this phenomenon, referred to as contrarian stock price reactions (see e.g. Kinney et al., 2002), is prevalent in each forecast error decile. 32\% (29\%) of the cumulated abnormal returns for extreme negative (positive) forecast error are negative (positive), increasing to $44 \%$ for slightly negative forecast errors (decile 6). Contrarian stock price reactions are thus a pervasive phenomenon that is also a noteworthy characteristic of the data in Figure 1, where the interquartile range of each forecast error decile CAR distribution overlaps zero.

We statistically investigate whether the probability of observing a positive (nega-

\footnotetext{
${ }^{1}$ Cumulated abnormal returns are compounded over a three-day window (day -1 to +1 ) around the earnings announcement day, starting one trading day before the earnings announcement. The market model parameters $(\alpha$ and $\beta$ ) for each firm are calculated for a period of 250 trading days, starting 20 trading days before the earnings announcement. Results do not change if we choose an event window of $[0,+1]$.
} 
tive) stock price reaction to a pessimistic (optimistic) consensus forecast exceeds the probability of observing a negative (positive) price reaction. To do so, we perform a sign test to confirm whether, using a binomial distribution, there is an equal chance of a positive (negative) reaction to a negative (positive) forecast error. Results in column (6) of Table 2 show that the probability of observing a positive (negative) stock price reaction to a negative (positive) forecast error is significantly higher than observing a negative (positive) return, except for decile 7, where the null hypothesis of equality could not be rejected.

Table 2 also shows the average of the explanatory variables defined in Table 1 for each forecast error decile. The extreme optimistic and pessimistic deciles in our sample tend to have similar analyst and stock characteristics. Decile 1 and 10 are characterized by small firms with lower analyst coverage, compared to firms in the middle deciles. Size and analyst coverage serve as a proxy for information diffusion. The low coverage and small size of extreme deciles shows that firms with low levels of information diffusion experience a larger stock price reaction around the earnings announcement day. Further analysis uncovers an interesting asymmetry: low coverage stocks react more sluggishly to bad news than to good news. Bad news might diffuse gradually to investors as corporate managers have an incentive to publish only good news on the announcement day in order to promote rising stock prices (Soffer et al., 2000).

Dispersion measures the disagreement among analysts and reflects the level of consensus among market participants about future earnings. A low dispersion corresponds to a greater analyst consensus. When dispersion is low (large), stock reactions are generally small (large). For instance, the average dispersion in decile 1 and 10 equals 0.671 and 0.882 , respectively, while for decile 5 it is 0.106 . This positive relationship suggests that the market reaction measures the inherent uncertainty in analysts' consensus forecasts. In turn, dispersion may be an observable proxy for the imprecision of analysts' consensus forecasts and, thereby, provides an ex ante signal about analysts' future forecast error (see e.g. Ackert and Athanassakos, 1997). 
Pre-announcement stock returns ( $P 1 R E T$ and $P 2 R E T)$ are generally low for extreme deciles. The extreme positive decile is composed, on average, of stocks that have performed badly over the last 12 months, whereas the middle deciles are composed of past winners. For instance, the average cumulated abnormal return of firms in decile 1 over the last 6 months equals 4.3\%, while the average performance of stocks in decile 5 increases to $8.6 \%$. Firms with extreme earnings forecast errors are also more likely to have a large beta (i.e. greater forecast error variability). As reported in column (5), the average $\beta$ equals 1.209 in decile 1 , slightly decreases to 0.991 in decile 8 to increase again in decile 10 with 1.184 . The $\alpha$ estimates follow a similar pattern. Overall, we can conclude that firms in extreme forecast error deciles share similar analyst, stock and risk characteristics: they are small, undervalued, performed badly in the past and have uncertain future earnings with low rates of coverage by analysts.

Insert Table 2 about here.

Insert Figure 1 about here.

Table 3 reports the mean of the quarterly consensus forecast error for each quintile of firms, ranked on analyst and firm characteristics. The correlation coefficients confirm the signs hypothesized above, except for the RegDum variable, which is positively correlated with analysts' error. The positive correlation between the current and lagged forecast error confirms that analysts fail to learn from the time series properties of earnings (Abarbanell and Bernard (1992); Ali et al. (1992); Mendenhall (1991)). Because this relation is not linear over quintiles, it could be more effective to distinguish between lagged positive and negative forecast errors in our prediction model. Comparison of the two sets of variables shows that the degree of association is stronger for the group of analysts' forecast variables than for the group of prior 
stock performance variables. In line with Elgers and Lo (1994), the relation between forecast error and prior stock performance (P1Ret and P2Ret) is increasing over quintiles, and most of the positive bias is concentrated in the quintiles associated with poor performing stocks (i.e. quintiles 1 and 2). The optimism bias is thus likely to be greater for firms having poor prior earnings performance. Consistent with Basu et al. (1999), analysts' forecasts in the fourth quarter are significantly more optimistic than forecasts for the other quarters.

The message contained in the data can easily be summarized. Despite the presence of contrarian stock price reactions, there exists a monotonic decreasing relationship between analysts' forecast error and abnormal returns around the earnings announcement. Firms with the lowest forecast errors are among the largest, less risky and more profitable. An important implication follows from this observation: analysts' forecast error is a reliable signal in a trading strategy and predicting the magnitude of analysts' forecast error has the potential to be rewarding.

Insert Table 3 about here.

\section{Prediction model and methodology}

We use a linear firm fixed effects model that regresses the forecast error on the variables discussed above. The results of our most general robust model (Model (2)) in Table 4 reveals that all estimated coefficients have the expected sign, except for size (Size) and the regulation dummy (RegDum). Our main interest is in the forecast performance of the model, however. For this, we estimate the model over rolling data windows of 3 years, each time moving ahead 1 quarter. We report in panel B the root mean squared forecast error (RMSFE), the mean absolute forecast error (MAFE) and the success ratio (SR), which computes the number of times a 
given model correctly predicts the sign of the actual forecast error:

$$
\begin{aligned}
R M S F E & =\left[\frac{1}{N} \sum_{j=1}^{N}\left(\widehat{f e}_{j, t}-f e_{j, t}\right)^{2}\right]^{\frac{1}{2}} \\
M A F E & =\frac{1}{N} \sum_{j=1}^{N}\left|\widehat{f e}_{j, t}-f e_{j, t}\right| \\
S R & =\frac{1}{N} \sum_{j=1}^{N} I\left[\widehat{f e}_{j, t} \cdot f e_{j, t}>0\right]
\end{aligned}
$$

where $f e_{j, t}$ and $\widehat{f e}_{j, t}$ are the actual forecast error and the predicted error for company $j$ for year-quarter $t$, respectively, and $I(\cdot)$ is the indicator function. As a benchmark, we also report these precision measures for the random walk model, assuming that the error made in quarter $t$ equals the error made in quarter $t-1$ (see Figure 3). Compared to this model, standard OLS fixed effects (Model (1)) has a clearly lower RMSFE, but similar MAFE and significantly worse success ratio (61\% versus $70 \%$ for the random walk model). This is due to the presence of a few extreme outlying observations in the forecast error data, as can be seen from the left boxplot in Figure 2 .

These extreme outlying observations affect the estimation of the model. For this reason, we opt to estimate the forecast model with robust fixed effects, as proposed by Bramati and Croux (2007). It consists in first robustly centering each variable with its median, followed by the robust MM estimation of the regression model on the centered data. The MM-estimators were introduced by Yohai (1987) and achieve simultaneously a high outlier robustness and a high level of efficiency. ${ }^{2}$

The robust estimation approach is not sufficient to safeguard the predictions against outliers in the forecast error series. Indeed, the extremes in the lagged forecast error series can have an influential impact on the actual forecast (see Figure

\footnotetext{
${ }^{2}$ We used the default implementation of the ROBUSTREG procedure for the MM method in SAS.
} 
3). We call these either good or bad leverage points; a good (bad) leverage point being an extremely large lagged forecast error that leads to an accurate (inaccurate) forecast. Good leverage points are no outliers and even improve the regression inference, as these points reduce standard errors of coefficient estimates.

We therefore apply a winsorizing method inspired by Gelper et al. (2009) that replaces outlying lagged forecast errors $\left(f e_{j, t-1}\right)$ by a more likely value based on the following procedure. At each quarter $t$, we divide the absolute difference between the lagged forecast error $\left(f e_{j, t-1}\right)$ and its median $\left(\operatorname{med}_{j, t-1}\right)$ by its median absolute deviation $\left(\operatorname{mad}_{j, t-1}\right)$. The last two variables are calculated based on the four most recent forecast errors in the same quarter as $t-1$. If this ratio exceeds $k$, the forecast error is signalled as outlying and takes the value as given by equation 4.1. A common choice for $k$ is $3 .^{3}$

$$
\widetilde{f e}_{j, t-1}=\operatorname{med}_{j, t-1}+\left[k \cdot \operatorname{mad}_{j, t-1} \cdot \operatorname{Sign}\left(f e_{j, t-1}-\operatorname{med}_{j, t-1}\right)\right]
$$

The rolling analysis accounts for the time-variation in the conditional mean and standard deviation of the forecast errors, while matching by quarter allows us to control for earnings seasonality (Stickel, 1989). The resulting winsorized series is shown in the right boxplot of Figure 2. We see that the filtering removes the majority of the extremes, but not all, since an extreme observation does not necessarily coincide with an outlier.

Columns 3 and 4 of Table 4 show the benefits of the robust methodology with respect to the classical forecast method. All estimated coefficients, except the Size variable, have the expected sign. The RMSFE and MAFE of the robust forecasts are significantly lower than when the classical fixed effects estimator is used or the random walk model. Concerning the complete sample, the MAFE is 0.607 for the least squares fixed effects estimator, and only 0.482 for the robust forecast. The

\footnotetext{
${ }^{3}$ Similar results are obtained for $k=2$.
} 
success ratio of the random walk model and the robust forecast are both at a high value of approximately $70 \%$.

A comparison between the prediction performance of the sample without leverage points and the performance of leverage points only suggests that the prediction error is mainly influenced by a few forecasts with a large lagged forecast error. The MAFE of the extreme values is 2.095 for the whole sample and the MAFE of the sample without the leverage points equals 0.390 . This is confirmed by Figure 2, where the distribution of analysts' lagged error has a fatter optimistic than pessimistic tail. As for the whole sample, the robust fixed effects model improves the prediction performance of the leverage points. The MAFE is 1.583 for the least squares fixed effects model, and 1.414 for the robust forecast.

The random walk model significantly benefits from winsorizing the extreme lagged forecast error: the MAFE of the leverage points decreases from 2.095 to 1.447. After winsorizing, it even performs better than the least squares model, with a MAFE of 1.447 versus 1.594. Winsorizing, however, slightly increases the prediction error of leverage points when using the least squares or robust methods. The RMSFE for the robust forecast increases from 1.414 to 1.417 .

In columns 4-6 we analyze the impact of the choice of variables on the explanatory power and forecast precision of the robust approach. We find that the forecast precision is little affected by dropping the stock-related performance variable from the regression. The lagged forecast variable seems to be useful, but not in the way it was expected. As a regressor, it only adds a little to the forecast precision. Its value comes especially as a selection tool that allows to identify leverage points. For model (2) the RMSFE drops from 2.668 to 1.833 when computing the forecast only for the stocks for which the lagged forecast error was not an outlier using $k=3$.

Predicting analysts' forecast error is a difficult task. Extreme values greatly influence the accuracy of our predictions. In particular, this section showed that large lagged forecast errors heavily affect the precision of our prediction models, making the robust regression approach essential in order to significantly improve 
the prediction accuracy of our prediction. We also showed that winsorizing proved to be a beneficial tool in predicting analysts' error, in particular in the case of the random walk model. In the next section, we attempt to derive profitable trading strategies for each of the following models: (i) random walk, (ii) random walk with conditional filtering $(k=3)$, (iii) robust fixed effects models and (iv) robust fixed effects models after winsorizing $(k=3)$. We consider the OLS model before and after winsorizing as the benchmark model. For each of the models (i-iv), we test for significant differences in the gross returns and Sharpe ratios with the OLS estimation procedure.

Insert Figures 2 and 3 about here.

Insert Table 4 about here.

\section{Trading strategies}

\subsection{Portfolio construction}

In this section, we determine whether investors can profit from the prediction of analysts' forecast error. We construct calendar-time portfolios based on the predicted forecast error. We first investigate the optimal trading horizon in stocks, when starting the trade five trading days before the earnings announcement. We analyze portfolio returns for holding periods ranging from one day up to 66 trading days, starting 5 trading days before the earnings announcement. Based on the optimal trading horizon, two trading strategies are defined. The first strategy, called the Magnitude strategy, exploits both the sign and magnitude of the predicted forecast error. For this purpose, we take a long (short) position on firms whose predicted forecast error for quarter $t$ is below (above) the $10 \%$ (90\%) quantile of the realized 
forecast error in quarter $t-1$. We use the distribution of quarter $t-1$ to assign decile ranks to avoid look-ahead bias given that the quarter $t$ distribution would not be known until the last company has announced its quarterly earnings. As a comparison, the second strategy considers the sign of the predicted forecast error only. This strategy is referred to as the Sign strategy. For each quarter between 1998 and 2010, we take a long (short) position in firms for which the forecast error is predicted to be negative (positive).

The calendar year is clustered in periods with intense activity in earnings reports. While the rest of the year few announcements are made, the months of January, May, July and September typically observe a high concentration of earnings reports on a daily basis. It is during these four periods that our trading strategies experience a high degree of turnover. The composition of the portfolio is thus likely to change on a daily basis. As a result, we construct equally weighted portfolios with daily rebalancing. The rest of the year, if no investable stocks are available, the proceeds are invested at the risk-free rate. To benchmark the performance of our trading strategies, we also calculate the profitability of perfect foresight strategies which assumes a perfect prediction of analysts' forecast error.

\subsection{Gross abnormal returns}

To determine whether the Sign and Magnitude strategies are profitable, we begin with calculating the gross daily portfolio return. Let $N_{\tau}$ be the number of firms in the portfolio at the close of trading on day $\tau$ and $R_{j, \tau}$ is the return on the stock for firm $j$ on day $\tau$. This gross daily portfolio return on day $\tau$ is then given by

$$
R_{\tau}=\sum_{j=1}^{N_{\tau}} w_{j, \tau} R_{j, \tau}
$$

where $w_{j, \tau}$ is the portfolio weight for firm $j$ on day $\tau$. This weight equals $1 / N_{\tau}$ if firm $j$ is in the portfolio and 0 otherwise.

For each month in our sample period, the daily returns $R_{\tau}$ are compounded over 
the $T$ trading days of the month to yield the monthly return series $R_{m}$. For each strategy, we report the average, standard deviation and Sharpe ratio of returns. As the risk free rate we take the one month T-bill risk free rate obtained from CRSP.

\subsection{Transaction costs $\&$ net abnormal returns}

The trading strategies require relatively high trading levels. We therefore investigate whether the strategies are still profitable after transaction costs. The daily portfolio turnover $\kappa_{\tau}$ is computed as the percentage of wealth traded that day :

$$
\kappa_{\tau}=\sum_{j=1}^{N}\left|w_{j, \tau+1}-w_{j, \tau^{+}}\right|
$$

where $w_{j, \tau^{+}}$is the portfolio weight before rebalancing at time $\tau+1$ and $w_{j, \tau+1}$ is the actual portfolio weight at time $\tau+1$.

The net return for an investor corresponds to the gross return performance, from which the estimated transaction costs are deducted. We use the transaction cost estimates provided by Balduzzi and Lynch (1999) and Keim and Madhavan (1998). Following Balduzzi and Lynch (1999), we set the transaction cost per dollar of portfolio value traded $f$ to either $0.1 \%$ or $0 \%$ for comparison. Balduzzi and Lynch (1999) also use a transaction cost of $0.01 \%$ that we do not report for the sake of brevity, but the results are available upon request. However, this transaction cost does not consider the size of the stocks traded. To alleviate this shortcoming, we also use the transaction cost of Keim and Madhavan (1998). Keim and Madhavan (1998) provide an estimate of the total round-trip transaction costs incurred by institutions in trading exchange-listed and Nasdaq stocks, broken down by firm size quintile. Using their numbers, we estimate the one-way transaction cost by measuring half the round-trip cost for each quintile - that is 0.2425 for the largest stocks ( $5^{\text {th }}$ quintile), 0.605 for the second largest stocks ( $4^{\text {th }}$ quintile), 0.94 for the medium sized stocks ( $3^{\text {rd }}$ quintile), 1.395 for the second smallest stocks ( $2^{\text {nd }}$ quintile) 
and 2.4375 for the smallest stocks ( ${ }^{\text {st }}$ quintile). ${ }^{4}$ Weighting these percentages by the fraction that each firm size classification makes up of total market capitalization (large firms comprise $81.869 \%$, the second largest firms $10.860 \%$, the medium sized firms $4.482 \%$, the second smallest firms $2.047 \%$ and the smallest firms $0.742 \%$ of our sample), we estimate the average transaction cost $f$ at $0.353 \%$ of share value traded. $^{5}$ In conjunction with the calculated turnover, these percentages $f$ can be used to provide an estimate of the impact of transaction costs on investment returns. The net portfolio return on day $\tau, R_{\tau}^{N}$, is given by (5.3).

$$
R_{\tau}^{N}=R_{\tau}-f \cdot \kappa_{\tau}\left(1+R_{\tau}\right)
$$

where $R_{\tau}$ is the gross monthly portfolio return defined in 5.1, $f$ is the transaction cost per dollar of portfolio value traded and $\kappa_{\tau}$ is the portfolio turnover on day $\tau$ defined in 5.2. The daily net returns $R_{\tau}^{N}$ are then compounded over the $T$ trading days of each month to yield a net monthly return $R_{m}^{N}$. As for the gross returns, we report the average and standard deviation of net monthly returns, as well as the annual Sharpe ratio after transaction costs.

As in Engle and Colacito (2005), we test for significant differences between the monthly portfolio return of each model with the monthly return obtained from the least squares Model (1) using a Diebold and Mariano (1995) type test. It regresses the daily differences between the performance measures of two models on a constant and tests whether the estimated constant is significantly different from zero using a Newey-West standard error. We also test for the difference in the Sharpe ratio with the OLS model using the test of Jobson and Korkie (1981) and Memmel (2003), implemented with Newey-West standard errors as proposed in Ledoit and Wolf

\footnotetext{
${ }^{4}$ All calculations assume summing the buy sided transaction costs with the sell sided transaction costs reported by Keim and Madhavan (1998) and an equal weighting of exchange-listed and Nasdaq firms, following Barber et al. (2001).

${ }^{5} 0.00742 \cdot 2.4375+0.02047 \cdot 1.395+0.04482 \cdot 0.94+0.10860 \cdot 0.605+0.81869 \cdot 0.2425=0.353$.
} 
(2008).

Finally, we report the risk adjusted returns for both strategies. Daily excess returns are compounded to monthly excess returns and regressed on monthly Fama French factors, obtained from Kenneth French's website.

$$
R_{m}^{e}=\alpha+\beta_{1} R_{m}^{M}+\beta_{2} S M B_{m}+\beta_{3} H M L_{m}+\beta_{3} M O M_{m}+\varepsilon_{m},
$$

with $R_{m}^{e}$ the monthly compounded excess return of the portfolio in month $m$. The Fama French factors comprise excess returns on the market portfolio $\left(R^{M}\right)$, a size factor $(S M B)$, a book-to-market factor $(H M L)$ and a momentum factor $(M O M)$. We test whether the intercept $(\alpha)$ is significantly different from zero using Newey-West standard errors.

\subsection{Results}

To gain insights into the profitability of the Magnitude strategy, we first display in Figure 4 the evolution of the average cumulative monthly return over various trading horizons under the assumption of perfect foresight. The investment period starts 5 trading days before the earnings announcement and incrementally increases by one day up to 60 days after the earnings announcement. We observe an overshooting pattern in returns around the announcement, which suggests that most of the profits could be reaped over a short term horizon, with an optimal total trading horizon of 7 trading days. For our sample period, if an investor could perfectly predict the magnitude of analysts' forecast error, he would have been able to earn a maximum average monthly return of $6.308 \%$, significant at a $99 \%$ level if he had a 7 trading

day horizon. One could argue that this return is explained by the market risk, size, book-to-market and price momentum characteristics of the stocks, but the Carhart intercept test in Panel A of Table 5 provides strong evidence of significant abnormal returns, with a highly significant monthly abnormal return of $6.533 \%$. After transaction costs of 0.353 , the net abnormal return of the Magnitude strategy 
still provides a high $4.637 \%$. This return pattern is consistent with analysts' forecast error being a reliable signal for future returns. A short term trading strategy based on the prediction of this signal could be highly rewarding.

Insert Figure 4 about here.

The results of such a trading strategy based on the predicted magnitude of analysts' error are reported in Table 5. Panel A of Table 5 reports the average monthly return of the Magnitude strategy based on the prediction of analysts' error without winsorizing. The robust fixed effects Model (2) conditional on analysts' and prior-stock performance variables yields the largest gross returns, with $1.418 \%$. After correcting for risk, the Carhart model shows a significant alpha at a $99 \%$ confidence interval, with a monthly abnormal return of $1.257 \%$. $^{6}$ This significant abnormal return shows that the Magnitude strategy is profitable to an investor, even after correcting for market, size and book-to-market risks.

We also report the results for the prediction of analysts' error using the OLS regression procedure. By doing so, we can evaluate the usefulness of the robust forecast methodology when predicting analysts' error. Results of the Jobson and Korkie (1981) test clearly confirm that the use of the robust method significantly increases the profitability of our prediction model. On the complete sample without winsorizing, the Sharpe ratio for Model (1) is negative with an excess return of $0.297 \%$ per unit of risk, while the Sharpe ratio of Model (2) is statistically larger, with $0.500 \%$ excess return per unit of risk. This result shows that, contrary to the long term prediction adopted by Hughes et al. (2008), investors could exploit publicly available information to initiate short term profitable trading strategies based on the robust prediction of the magnitude of analysts' forecast error.

\footnotetext{
${ }^{6}$ In view of results in Sadka and Scherbina (2007), who show that stocks with high dispersion of analysts' forecast error are less liquid, we test whether we still obtain gross abnormal returns if we augment the Carhart model with the Pastor and Stambaugh (2003) liquidity factor. Results remain unaltered for the Magnitude and Sign strategies.
} 
In Models (1) and (2) analyst and prior-stock performance variables are used to predict analysts' forecast error. In Models (3) and (4), we analyze the impact of including these two categories on the profitability of our trading strategy. Model (3) excludes firm-specific variables and yields a Sharpe ratio of 0.398 and Model (4), that includes firm-specific variables, only reports a ratio of 0.335 . The robust joint estimation of analysts' forecast and firm-specific variables thus seems necessary in order to yield a Sharpe ratio that is statistically higher than the Sharpe ratio of the OLS estimates of Model (1). In addition, the joint estimation also proves to be more profitable than the random walk model. The random walk provides a better gross performance than the OLS estimates of Model (1), but its Sharpe ratio is only one third of Model (1). This evidence shows that the information gathered to predict analysts' forecast error is valuable to an investor, but these variables seem to add value only when they are jointly estimated.

Our results are evidence of a market that is semistrong inefficient, before transaction costs. It suggests that investors can exploit the post-earnings announcement drift by predicting analysts' forecast errors, using publicly available information. However, returns thus far have been gross of the transaction costs associated with trading. As we show in column (5) of Table 5, our trading strategy requires a great deal of trading that may considerably impact the profitability of the strategy. The average daily turnover equals $16.737 \%$ of total portfolio wealth for the robust Model (2) and $16.554 \%$ for robust Model (4). Assuming that large investors have a level of transaction costs of $0.100 \%$, Table 5 shows that investors would be able to yield a significant net abnormal return of $0.894 \%$ per month by trading on the magnitude of the predicted error using Model (2). Large institutional investors typically negotiate prices directly with dealers, making their transaction costs lower than these of the average investor (see e.g. Keim and Madhavan, 1997). In addition, transaction costs are continuously under pressure which of course increases the likelihood that implementing our trading strategy will result in net abnormal returns. If transaction costs would be $0.353 \%$, all models yield insignificant abnormal returns, except for 
the random walk and the OLS estimates of Model (1) and (5) that are respectively significantly negative at a 95, 99 and 90\% confidence level.

We showed in Figure 2 that the forecast error data is composed of extreme outlying observations that affect the estimation of the models. We now examine whether we are able to improve the profitability of our trading strategy by winsorizing the lagged forecast error. Panel B of Table 5 reports the summary statistics of the Magnitude strategy with winsorized leverage points. Except for Model (3), winsorizing lagged forecast errors slightly increases the profitability. The gross abnormal return of the robust fixed effects Model (2) increases to $1.380 \%$, realizing an increase of 12.3 basis points. The least squares estimates of Model (1) perform better, but the average gross return remains negative with a gross abnormal return of $-0.781 \%$. The greatest improvement is observed for the forecasts based on the random walk model. The average monthly gross return nearly doubles to $1.120 \%$ and the Sharpe ratio significantly increases from 0.281 to 0.534 . This result is consistent with the improvement in the predictability of the random walk model after winsorizing. If transaction costs are equal to $0.100 \%$ (or below), the robust Model (2) would still earn a significant net abnormal return of (at least) 1.018\%. If the level of transaction costs is increased to $0.353 \%$, the net abnormal return of Model (2) is reduced to an insignificant abnormal return of $0.110 \%$. We can conclude that winsorizing on the lagged forecast error proves to be valuable for an investor as it increases the profitability of the investment strategy. Overall, we showed that the strategy based on the prediction of the magnitude of analysts' error could yield significant gross abnormal returns. Robust estimation and winsorising have proven to be valuable, but the net profitability of the strategy is to some extent dependent of the level of transaction costs that an investor would incur.

Insert Table 5 about here.

We now compare this performance with a trading strategy based on the prediction of the sign of analysts' error, as in Dowen and W. Bauman (1995). As shown 
in Figure 4, a strategy based on the sign of analysts' error highly underperforms a strategy based on the magnitude of analysts' error over all horizons. If an investor with a trading horizon of 7 trading days could perfectly predict the sign of analysts' error, he would have been able to earn a maximum average monthly return of $3.630 \%$ over our sample period. This represents a difference in gross monthly return of $2.903 \%$ with the Magnitude strategy.

The outperformance of the Magnitude strategy clearly emphasizes the superior value of a model that predicts not only the sign of analysts' error but also its magnitude. The sources of the higher net profitability of the Magnitude strategy are threefold. First, as showed in Table 2, there exists a monotonic stock price relation between analysts' forecast error and the stock price reaction. With a prediction of the magnitude of the error, the investor can distinguish between overly optimistic/pessimistic forecasts and define a trading strategy that focuses on firms with a large forecast error. Second, we observed that the probability of a positive (negative) stock price reaction decreases (increases) as the error decreases. Capturing both the sign and the magnitude of the error gives the opportunity of trading in stocks for which the error presents the highest likelihood of triggering a stock price reaction in the right direction (that is, positive returns for a pessimistic consensus and negative returns for an optimistic consensus). Third, as shown in column (5) of Tables 5 and 6 , the magnitude strategy requires a lower portfolio turnover. With an average turnover of $28.128 \%$ on a daily basis, the Sign strategy demands much more trading that the Magnitude strategy, which requires a lower $22.670 \%$ with perfect foresight.

Panel A of Table 6 reports the results for the Sign strategy based on the predicted sign of the forecast error. We find that only the benchmark random walk model yields significant gross abnormal returns with $0.808 \%$. With a transaction cost of $0.100 \%$, all models, except for the OLS model, present insignificant abnormal returns. With an abnormal return of $-0.939 \%$, the loss incurred when using the OLS procedure becomes significant at a $95 \%$ confidence level. Increasing the cost 
to $0.353 \%$ makes the abnormal returns of all models significantly negative. Panel B reports the results of the strategy after winsorizing. As for the original sample, the net abnormal returns after winsorizing on the lagged forecast error remain insignificant after a cost of $0.100 \%$ and become significantly negative after a cost of $0.353 \%$. As a result, we confirm that a robust prediction model that forecasts not only the sign but also the magnitude of analysts' error adds considerable value to an investor.

Insert Table 6 about here.

\section{Conclusion}

The sluggish reaction to earnings announcements and the subsequent post-earnings announcement drift remain striking challenges to the concept of market efficiency. In this study, we examined whether investors could earn short-term profits (before and after transaction costs) around the earnings announcement day by using publicly available information to make short term predictions of financial analysts' forecast error. We showed that investors can exploit publicly available information to initiate short term profitable trading strategies based on the robust prediction of the magnitude of analysts' forecast error. Over the 1998-2010 period, going long in stocks with the most predicted pessimistic forecast and short in stocks with the most predicted optimistic forecast yields significant profits with an annual gross abnormal return of $16.56 \%$ over a 7 -day trading horizon, starting 5 trading days before the earnings announcement day. We further showed that predicting the magnitude of analysts' forecast error considerably increases the profitability of our trading strategies, while a strategy that merely trades on the sign of the predicted error yields abnormal returns that are statistically insignificant. We also illustrated that the robust estimation procedure should be employed in order to obtain such profits. 
The traditional OLS procedure has a poor out-of-sample prediction performance and generates insignificant negative abnormal returns.

Despite the high turnover, the strategy based on the magnitude of analysts' error yields an significant annual abnormal return of $12.216 \%$ as long as transaction costs do not exceed $0.100 \%$ of share value traded. Although this level of transactions costs might not be attainable for all investors (especially retail investors), it may still be feasible for large institutional investors who can negotiate prices directly with dealers (see e.g. Keim and Madhavan, 1997). This is corroborated by the fact that transaction costs are continuously under pressure. It can thus be expected that for these investors, trading on the predicted forecast error is profitable.

Regardless of the specific trading strategy or level of transaction costs, this paper has shown the importance of using robust estimation techniques for the prediction of financial analysts' forecast error. An interesting direction for further research would be to analyze in greater detail the identified outliers, as they might provide important insights into the dynamics of the forecast strategy applied by financial analysts, and might also pose challenging questions in terms of their treatment in the econometric analysis of analyst behavior.

\section{Bibliography}

Abarbanell, J. S. and V. L. Bernard (1992). Tests of analysts' overreaction/underreaction to earnings information as an explanation for anomalous stock price behavior. Journal of Finance 4\%, 1181-1207.

Ackert, L. F. and G. Athanassakos (1997). Prior uncertainty, analyst bias and subsequent abnormal returns. Journal of Financial Research 2, 263-273.

Ali, A., A. Klein, and J. Rosenfeld (1992). Analysts' use of information about permanent and transitory earnings components in forecasting annual eps. The Accounting Review 6\%, 183-198.

Balduzzi, P. and A. Lynch (1999). Transaction costs and predictability: some utility cost calculations. Journal of Financial Economics 52, 47-78. 
Barber, B., R. Lehavy, M. McNichols, and B. Trueman (2001). Can investors profit from the prophets? Security analyst recommendations and stock returns. The Journal of Finance 41, 87-117.

Basu, S., L. Hwang, and C. Jan (1999). Auditor conservatism and analysts' fourth quarter earnings forecasts. Unpublished.

Beaver, W., B. Cornell, W. R. Landsman, and S. R. Stubben (2008). The impact of analysts' forecast errors and forecast revisions on stock prices. Journal of Business Finance and Accounting 35, 709-740.

Bhushan, R. (1989). Firm characteristics and analyst following. Journal of Accounting and Economics 11, 255 - 274.

Boehmer, E., J. Musumeci, and A. B. Poulsen (1991). Event-study methodology under conditions of event-induced variance. Journal of Financial Economics 30, $253-272$.

Bramati, M. C. and C. Croux (2007). Robust estimators for the fixed effects panel data model. Econometrics Journal 10, 521-540.

Das, S., C. B. Levine, and S. Sivaramakrishnan (1998). Earnings predictability and bias in analysts' earnings forecasts. The Accounting Review 73, 277-294.

Dichev, I. D. and V. W. Tang (2009). Earnings volatility and earnings predictability. Journal of Accounting and Economics 47, 160-181.

Diebold, F. X. and R. S. Mariano (1995). Comparing predictive accuracy. Journal of Business and Economic Statistics 13, 253-263.

Dowen, R. J. and S. W. Bauman (1995). Financial statements, investment analyst forecasts and abnormal returns. Journal of Business Finance 83 Accounting 22, $431-447$.

Elgers, P. T. and M. H. Lo (1994). Reductions in analysts' annual earnings forecast errors using information in prior earnings and security returns. Journal of Accounting Research 32, 290-303.

Engle, R. F. and R. Colacito (2005). Testing and valuing dynamic correlations for asset allocation. Journal of Business and Economic Statistics 24, 238-253.

Francis, J. and D. Philbrick (1993). Analysts' decisions as products of a multi-task environment. Journal of Accounting Research 31, 216-230.

Frankel, R. and C. M. C. Lee (1998). Accounting valuation, market expectation, and cross-sectional stock returns. Journal of Accounting and Economics 25, 283 -319 . 
Gelper, S., R. Fried, and C. Croux (2009). Robust forecasting with exponential and holt-winters smoothing. Journal of Forecasting 29, 285-300.

Gu, Z. and J. S. Wu (2003). Earnings skewness and analyst forecast bias. Journal of Accounting and Economics 35, 5-29.

Hotta, L. K. (1993). The effect of additive outliers on the estimates from aggregated and disaggregated arima models. International Journal of Forecasting 9, 85-93.

Hughes, J., J. Liu, and W. Su (2008). On the relation between predictable market returns and predictable analyst forecast errors. Review of Accounting Studies 13, 266-291.

Jegadeesh, N., J. Kim, S. D. Krische, and C. M. C. Lee (2004). Analyzing the analysts: When do recommendations add value? Journal of Finance 59, 10831124 .

Jobson, J. D. and B. M. Korkie (1981). Performance hypothesis testing with the sharpe and treynor measures. Journal of Finance 36, 889-908.

Keim, D. B. and A. Madhavan (1997). Transaction costs and investment style: inter-exchange analysis of insitutional equity trades. Journal of Financial Economics 46, 263-292.

Keim, D. B. and A. Madhavan (1998). The cost of institutional equity trades. Financial Analysts Journal 54, 50-69.

Kinney, W., D. Burgstahler, and R. Martin (2002). Earnings surprise "materiality" as measured by stock returns. Journal of accounting research 40, 1297-1329.

Ledoit, O. and M. Wolf (2008). Robust performance hypothesis testing with the sharpe ratio. Journal of Empirical Finance 15, 850-859.

Ledoter, J. (1989). The effect of additive outliers on the forecasts from arima models. International Journal of Forecasting 5, 231-240.

Memmel, C. (2003). Performance hypothesis testing with the sharpe ratio. Finance Letters 1, 21-23.

Mendenhall, M. R. (1991). Evidence on the possible underweighting of earningsrelated information. Journal of Accounting Research 29, 170-179.

Pastor, L. and R. F. Stambaugh (2003). Liquidity risk and expected stock return. Journal of Political Economy 111, 642-685.

Patton, A. J. and A. Timmerman (2010). Monotonicity in asset returns: New tests with applications to the term structure, the CAPM and portfolios sorts. Journal of Financial Economics 98, 605-625. 
Sadka, R. and A. Scherbina (2007). Analyst disagreement, mispricing and liquidity. The Journal of Finance 62, 2367-2403.

Soffer, L. C., S. R. Thiagarajan, and B. R. Walther (2000). Earnings preannouncement strategies. Review of Accounting Studies 5, 5-26.

Stickel, S. E. (1989). The timing of and incentives for annual earnings forecasts near interim earnings announcements. Journal of Accounting and Economics 11, 275-292.

Wieland, M. M. (2011). Identifying consensus analysts' earnings forecasts that correctly and incorrectly predict an earnings increase. Journal of Business Finance E Accounting 38, 574-600.

Yohai, V. J. (1987). High breakdown-point and high efficiency robust estimates for regression. The Annals of Statistics 15, 642-656. 
Figure 1: Median and interquartile range per forecast error decile

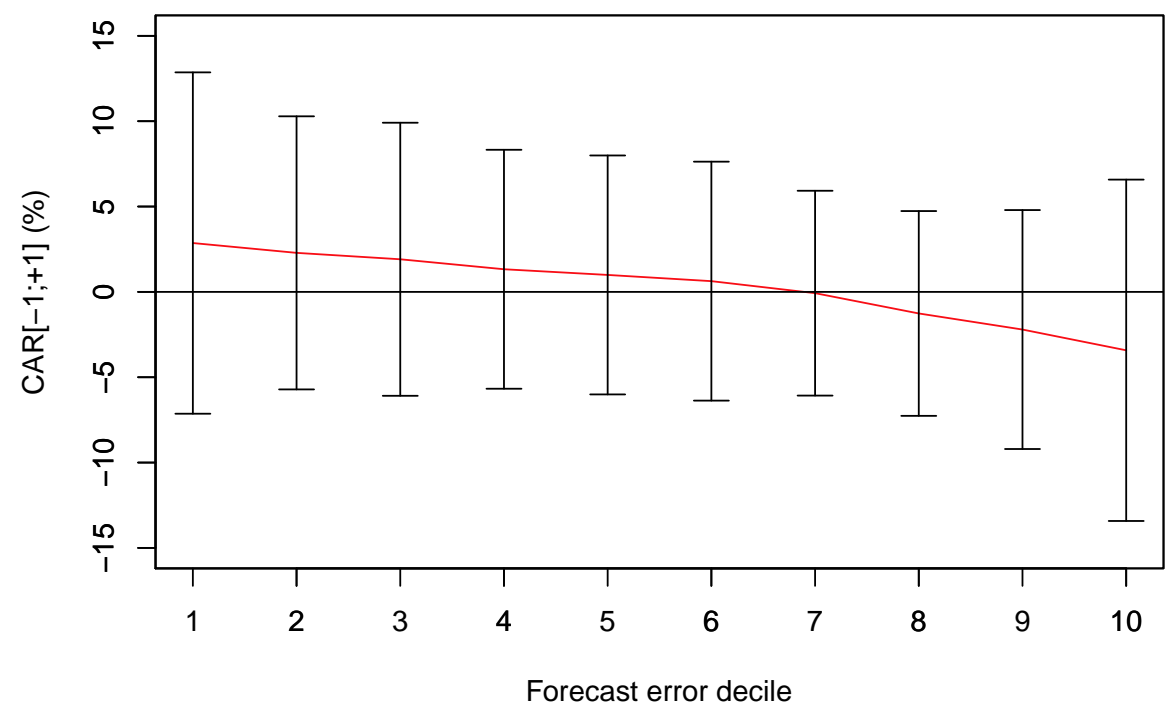

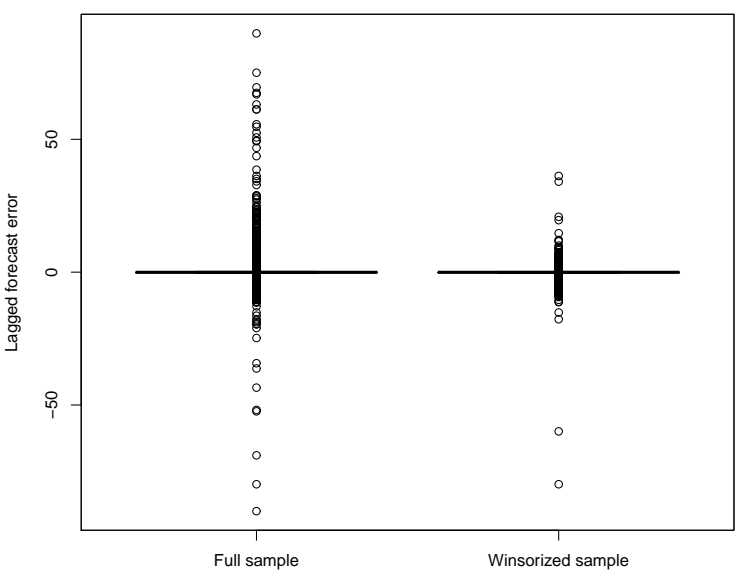

Figure 2: Lagged fe boxplot

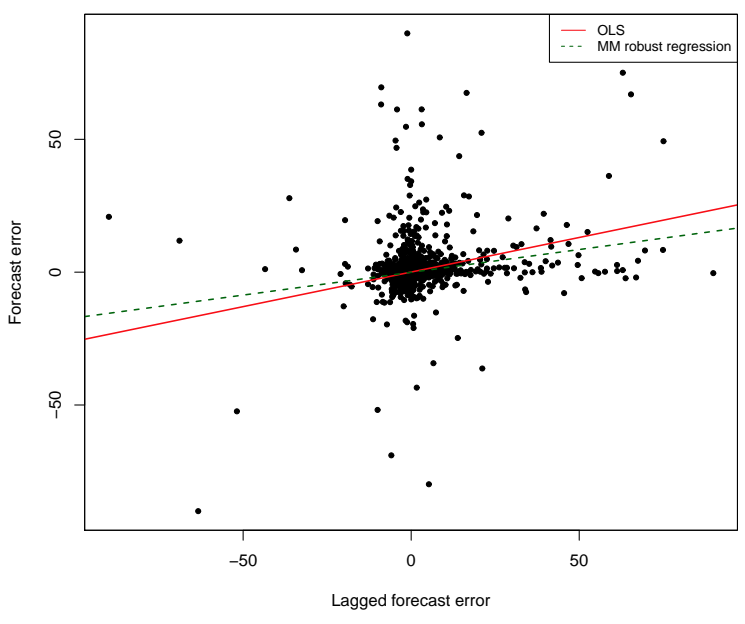

Figure 3: $f e$ on lagged $f e$ scatter plot

Figure 2 graphically depicts the lagged forecast error for the full sample (left boxplot) and the winsorized sample (right boxplot). Figure 3 shows the forecast error in function of the lagged forecast error. In addition to the OLS regression line, the dotted line depicts the MM robust regression line. 
Figure 4: Perfect foresight Sign \& Magnitude strategies

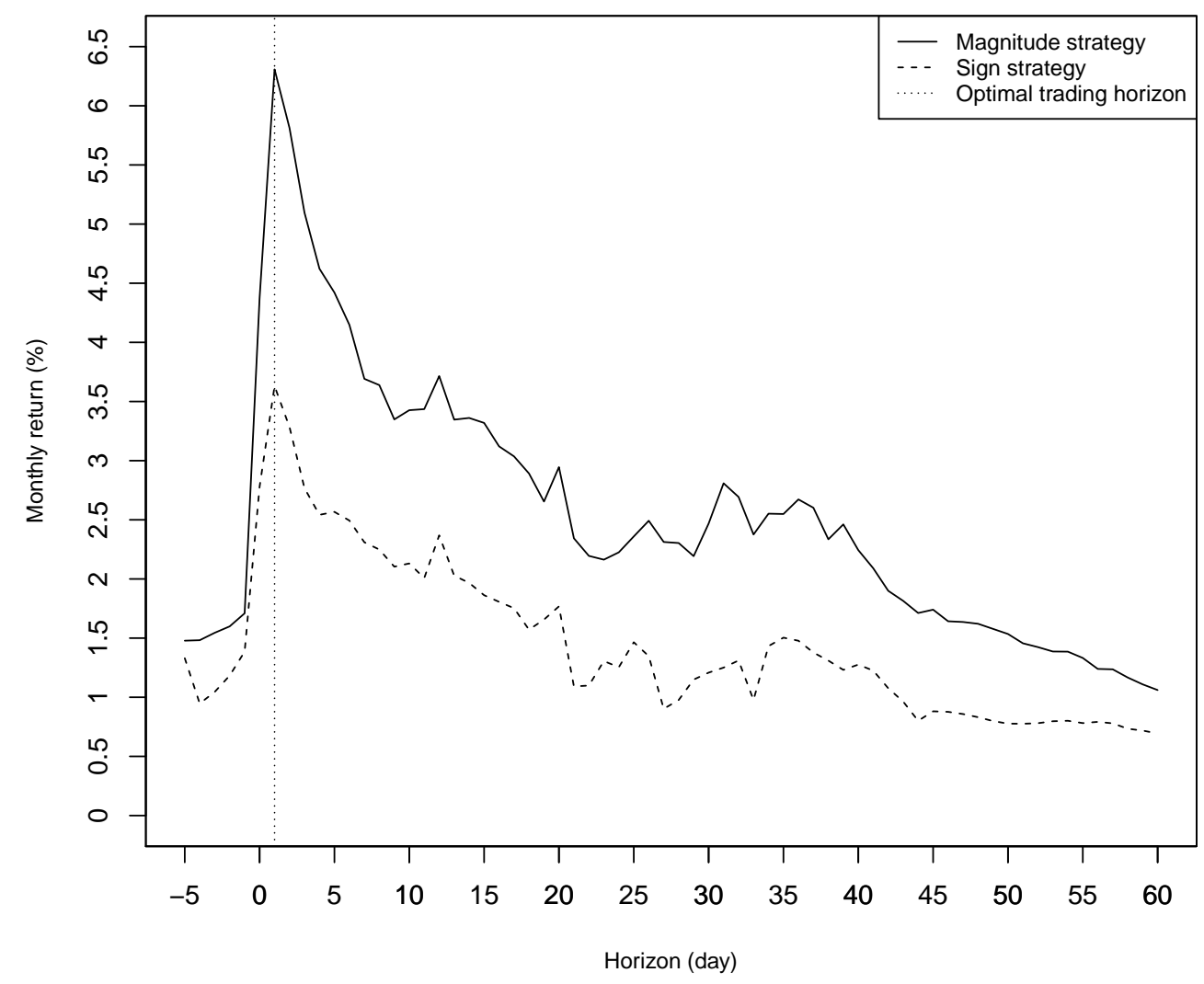




\section{Table 1: Variables and their definitions}

\section{Dependent variable}

Forecast error

$f e_{j, t}$ : Difference between the consensus EPS forecast $\left(\right.$ Consensus $\left._{j, t}\right)$ and reported EPS $\left(\right.$ Actual $_{j, t}$ ) for firm $j$ for quarter $t$, scaled by the closing price on the day before the forecast date and expressed as a percentage. Consensus $_{j, t}$ is measured as the median of analysts' last earnings forecasts for company $j$ in quarter $t$ outstanding 5 trading days prior to the earnings announcement.

\section{Analysts' forecast variables}

Lagged forecast error $(+) \quad f e_{j, t-1}$ : The EPS forecast error made by analysts for firm $j$ at quarter $t-1$, expressed in percentage.

Lagged positive $\mathrm{FE}(+) \quad$ Pos. $f e_{j, t-1}$ : The positive forecast error made by analysts for company $j$ in quarter $t-1$, expressed in percentage.

Lagged negative FE $(+) \quad N e g . f e_{j, t-1}$ : The negative forecast error made by analysts for company $j$ in quarter $t-1$, expressed in percentage.

Dispersion (+)

$\operatorname{Disp}_{j, t}$ : Standard deviation of analysts' forecasts included in the consensus for firm $j$ in quarter $t$, expressed in percentage.

Coverage (?)

$\operatorname{Cov}_{j, t}$ : The logarithm of the number of analysts' forecasts included within the consensus for firm $j$ at quarter $t$.

\section{Prior stock performance}

Lagged size (-)

Size $_{j, t-1}$ : The logarithm of firm $j$ market capitalization at the end of quarter $t$.

Lagged cumulated stock returns (-) a) Market-adjusted cumulative return for the preceding two quarters (quarter -2) for firm $j$ in quarter $t$ :

$P 1 \operatorname{Ret}_{j, t}=\left\{\left[\prod_{\tau=t-2}^{t}\left(1+R_{j, t, \tau}\right)\right]-1\right\}-\left\{\left[\prod_{\tau=t-2}^{t}\left(1+R_{t, \tau}^{M}\right)\right]-1\right\}$.

b) Market-adjusted cumulative return for the second preceding two quarters (quarter -4 through -2 ) for firm $j$ in quarter $t$ :

$P 2 \operatorname{Ret}_{j, t}=\left\{\left[\prod_{\tau=t-4}^{t-2}\left(1+R_{j, t, \tau}\right)\right]-1\right\}-\left\{\left[\prod_{\tau=t-4}^{t-2}\left(1+R_{t, \tau}^{M}\right)\right]-1\right\}$.

where $R_{j, t, \tau}$ is the return of stock $j$ on day $\tau$ of quarter $t$

where $R_{t, \tau}^{M}$ is the S\&P500 value-weighted index return on day $\tau$ in quarter

Lagged earnings-to-price (-) $\quad E P_{j, t-1}$ : Earnings to price ratio for firm $j$ at quarter $t-1$, expressed in percentage.

\section{Control variables}

Fourth quarter $(+)$

Regulation dummy (-)
$Q 4_{t}$ : Dummy that takes the value of 1 if the forecast is made for the fourth quarter earnings, and zero otherwise.

RegDum $t_{t}$ : Dummy that takes the value of 1 if the forecast is made after Regulation Fair Disclosure coming into force on October $23^{\text {th }} 2000$, and zero otherwise. 


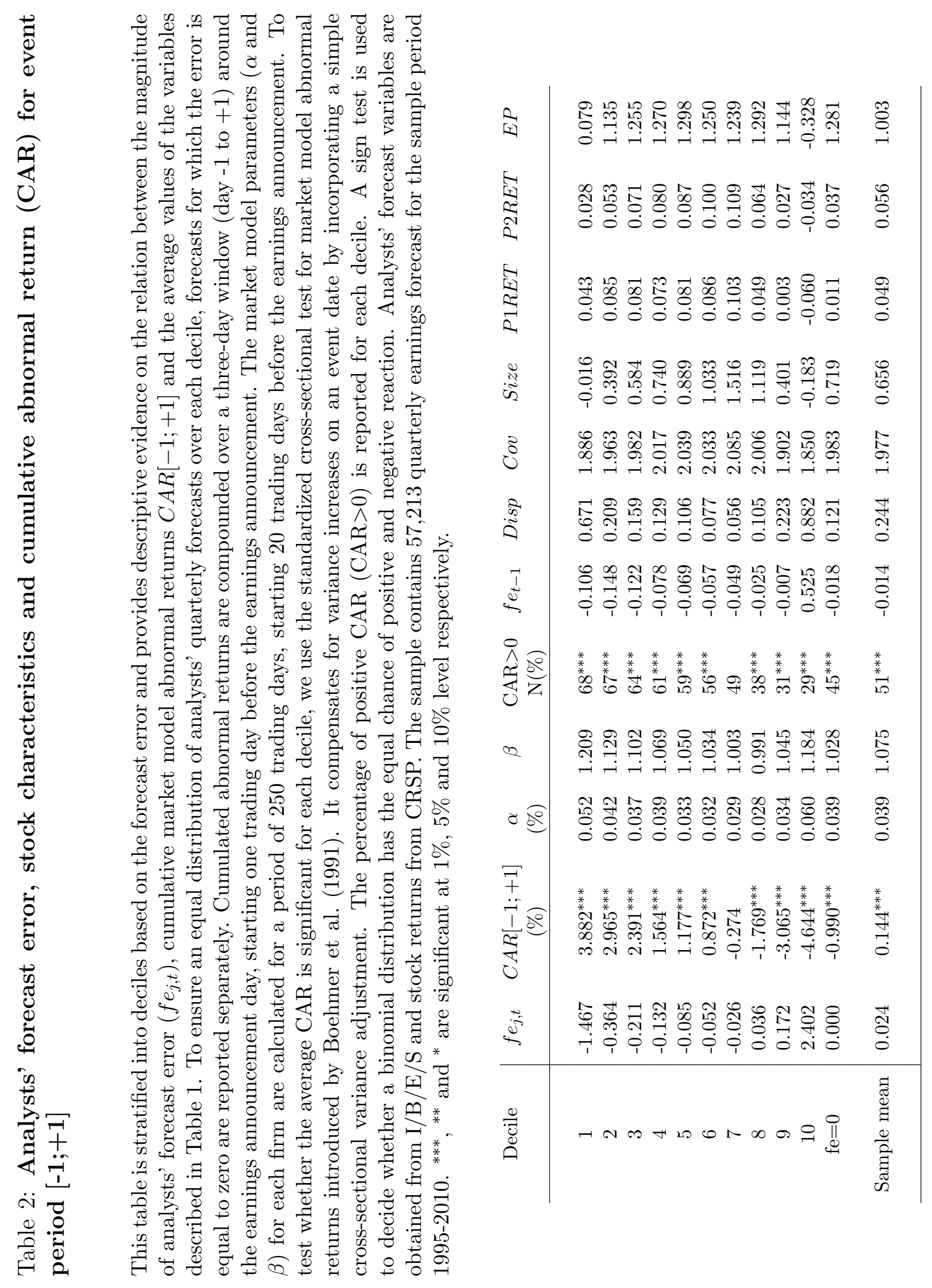




\section{Table 3: Consensus forecast error grouped by analyst and stock attributes}

Table 3 reports cross-sectional mean (standard deviation) of the quarterly consensus forecast error for each quintile of firms, ranked on each analyst and firm characteristic. Each characteristic and its expected relation with analysts' forecast error is specified in Table 1. Forecast error standard deviation is reported in brackets. The last column reports the Pearson correlation coefficient. ${ }^{* * *},{ }^{* *}$ and ${ }^{*}$ are significant at $1 \%, 5 \%$ and $10 \%$ level respectively.

\begin{tabular}{|c|c|c|c|c|c|c|}
\hline \multirow[b]{2}{*}{ Grouped by } & \multicolumn{5}{|c|}{ Quintile } & \multirow{2}{*}{$\begin{array}{c}\text { Pearson } \\
\text { Correlation }\end{array}$} \\
\hline & 1 & 2 & 3 & 4 & 5 & \\
\hline $\mathrm{N}$ & 11,442 & 11,444 & 11,441 & 11,444 & 11,442 & \\
\hline \multicolumn{7}{|c|}{ Dependent variable } \\
\hline$f e$ & $\begin{array}{l}-0.833 \\
(1.924)\end{array}$ & $\begin{array}{l}-0.143 \\
(0.042)\end{array}$ & $\begin{array}{l}-0.048 \\
(0.018)\end{array}$ & $\begin{array}{c}0.007 \\
(0.016)\end{array}$ & $\begin{array}{c}1.136 \\
(4.499)\end{array}$ & \\
\hline \multicolumn{7}{|c|}{ Analysts' forecast variables } \\
\hline$f e_{t-1}$ & $\begin{array}{l}-0.166 \\
(2.560)\end{array}$ & $\begin{array}{l}-0.067 \\
(0.710)\end{array}$ & $\begin{array}{l}-0.043 \\
(0.273)\end{array}$ & $\begin{array}{l}-0.004 \\
(0.744)\end{array}$ & $\begin{array}{c}0.399 \\
(4.252)\end{array}$ & $0.167^{* * *}$ \\
\hline Disp & $\begin{array}{l}-0.046 \\
(0.212)\end{array}$ & $\begin{array}{l}-0.064 \\
(0.214)\end{array}$ & $\begin{array}{l}-0.078 \\
(0.561)\end{array}$ & $\begin{array}{l}-0.069 \\
(1.413)\end{array}$ & $\begin{array}{c}0.376 \\
(4.837)\end{array}$ & $0.134^{* * *}$ \\
\hline Cov & $\begin{array}{c}0.070 \\
(2.575)\end{array}$ & $\begin{array}{c}0.001 \\
(2.189)\end{array}$ & $\begin{array}{c}0.038 \\
(2.204)\end{array}$ & $\begin{array}{c}0.031 \\
(2.671)\end{array}$ & $\begin{array}{l}-0.018 \\
(1.692)\end{array}$ & $-0.010^{* * *}$ \\
\hline \multicolumn{7}{|c|}{ Prior stock-related performance } \\
\hline Size & $\begin{array}{c}0.228 \\
(3.667)\end{array}$ & $\begin{array}{l}-0.012 \\
(2.459)\end{array}$ & $\begin{array}{l}-0.045 \\
(1.570)\end{array}$ & $\begin{array}{l}-0.009 \\
(1.831)\end{array}$ & $\begin{array}{l}-0.043 \\
(0.766)\end{array}$ & $-0.038^{* * *}$ \\
\hline$P 1$ Ret & $\begin{array}{c}0.273 \\
(3.840)\end{array}$ & $\begin{array}{l}-0.021 \\
(1.292)\end{array}$ & $\begin{array}{l}-0.033 \\
(1.292)\end{array}$ & $\begin{array}{l}-0.073 \\
(1.058)\end{array}$ & $\begin{array}{l}-0.028 \\
(2.582)\end{array}$ & $-0.057^{* * *}$ \\
\hline P2Ret & $\begin{array}{c}0.219 \\
(3.746)\end{array}$ & $\begin{array}{c}0.025 \\
(1.936)\end{array}$ & $\begin{array}{l}-0.017 \\
(1.403)\end{array}$ & $\begin{array}{l}-0.042 \\
(1.612)\end{array}$ & $\begin{array}{l}-0.066 \\
(1.885)\end{array}$ & $-0.044^{* * *}$ \\
\hline$E P$ & $\begin{array}{c}0.251 \\
(4.262)\end{array}$ & $\begin{array}{l}-0.034 \\
(1.163)\end{array}$ & $\begin{array}{l}-0.050 \\
(0.470)\end{array}$ & $\begin{array}{l}-0.028 \\
(1.014)\end{array}$ & $\begin{array}{l}-0.020 \\
(2.262)\end{array}$ & $-0.107^{* * *}$ \\
\hline \multicolumn{7}{|l|}{ Others } \\
\hline & \multicolumn{2}{|c|}{ RegDum = 0} & & \multicolumn{2}{|c|}{ RegDum = 1} & \\
\hline RegDum & \multicolumn{2}{|c|}{$\begin{array}{l}-0.012 \\
(0.917) \\
\mathrm{Q} 4=0\end{array}$} & & \multicolumn{2}{|c|}{$\begin{array}{c}0.033 \\
(2.520) \\
\mathrm{Q} 4=1\end{array}$} & $0.008^{* *}$ \\
\hline$Q 4$ & \multicolumn{2}{|c|}{$\begin{array}{c}0.001 \\
(2.054)\end{array}$} & & \multicolumn{2}{|c|}{$\begin{array}{c}0.116 \\
(3.025)\end{array}$} & $0.020^{* * *}$ \\
\hline
\end{tabular}




\section{Table 4: In sample OLS and robust regression estimates and out-of-sample performance}

Panel A of this table presents the in-sample robust regression results for quarterly forecast for the period 1995-2010. Prediction variables are described in Table 1. Panel B reports the out-of-sample performance measures of the forecast error prediction for the MM robust and OLS regressions. The out-of-sample predictive performances are examined using the root mean square forecast error measure (RMSFE), the mean absolute forecast error (MAFE), and the success ratio (SR), which computes the percentage of correct predictions of the sign of the actual forecast error. ${ }^{* * *},{ }^{* *}$ and ${ }^{*}$ indicates a significance at $1 \%, 5 \%$ and $10 \%$ level respectively.

\begin{tabular}{|c|c|c|c|c|c|c|}
\hline Variables & Expected sign & $\begin{array}{l}\text { Model (1) } \\
\text { OLS }\end{array}$ & $\begin{array}{c}\text { Model (2) } \\
\text { Robust }\end{array}$ & $\begin{array}{c}\text { Model (3) } \\
\text { Robust }\end{array}$ & $\begin{array}{c}\text { Model (4) } \\
\text { Robust }\end{array}$ & $\begin{array}{c}\text { Model (5) } \\
\text { OLS }\end{array}$ \\
\hline \multicolumn{7}{|c|}{ Analysts' forecasts variables } \\
\hline Pos.fe $e_{j, t-1}$ & + & $0.106^{* * *}$ & $0.003^{* *}$ & -0.001 & & \\
\hline$N e g . f e_{j, t-1}$ & + & $0.223^{* * *}$ & $0.129^{* * *}$ & $0.136^{* * *}$ & & \\
\hline Disp & + & $0.376^{* * *}$ & $0.024^{* * *}$ & $0.021^{* * *}$ & & \\
\hline $\mathrm{Cov}$ & $?$ & $0.064^{* *}$ & $-0.013^{* * *}$ & -0.001 & & \\
\hline \multicolumn{7}{|c|}{ Prior stock-related performance } \\
\hline Size & - & $-0.145^{* * *}$ & $0.021^{* * *}$ & & $0.020^{* * *}$ & \\
\hline P1Ret & - & $-0.108^{* * *}$ & $-0.031^{* * *}$ & & -0.045 & \\
\hline P2Ret & - & $-0.146^{* * *}$ & $-0.007^{* *}$ & & $-0.004^{* * *}$ & \\
\hline $\mathrm{EP}$ & - & $0.028^{* * *}$ & $0.004^{* * *}$ & & -0.001 & \\
\hline \multicolumn{7}{|l|}{ Others } \\
\hline RegDum & - & -0.008 & $-0.008^{* * *}$ & $-0.006^{* * *}$ & $0.004^{* *}$ & $-0.015^{* * *}$ \\
\hline Q4 & + & $0.089^{* * *}$ & $0.004^{* *}$ & $0.004^{* *}$ & $-0.014^{* * *}$ & 0.002 \\
\hline$R^{2}(\%)$ & & 3.58 & 1.09 & 0.90 & 0.43 & 0.11 \\
\hline \multicolumn{7}{|c|}{ Panel B - Out-of-sample regression performance } \\
\hline & Random Walk & Model (1) & Model (2) & Model (3) & Model (4) & Model (5) \\
\hline \multicolumn{7}{|c|}{ All predictions of $f e_{j, t}-N=26,176$} \\
\hline RMSE & 3.093 & 2.684 & 2.668 & 2.663 & 2.673 & 2.679 \\
\hline MAFE & 0.606 & 0.607 & 0.482 & 0.482 & 0.483 & 0.524 \\
\hline $\operatorname{SR}(\%)$ & 70.198 & 61.285 & 70.034 & 71.042 & 70.114 & 68.043 \\
\hline \multicolumn{7}{|c|}{ Predictions of $f e_{j, t}$ when $f e_{j, t-1}$ is no leverage point $(k=3)-N=22,861$} \\
\hline RMSE & 1.996 & 1.916 & 1.833 & 1.835 & 1.835 & 1.904 \\
\hline MAFE & 0.390 & 0.465 & 0.347 & 0.347 & 0.347 & 0.390 \\
\hline $\operatorname{SR}(\%)$ & 70.662 & 61.975 & 70.334 & 71.493 & 70.557 & 68.357 \\
\hline \multicolumn{7}{|c|}{ Prediction of $f e_{j, t}$ when $f e_{j, t-1}$ is a leverage point (no winsorizing) $(k=3)-N=3,315$} \\
\hline RMSE & 6.932 & 5.618 & 5.747 & 5.724 & 5.761 & 5.628 \\
\hline MAFE & 2.095 & 1.583 & 1.414 & 1.413 & 1.420 & 1.448 \\
\hline $\operatorname{SR}(\%)$ & 66.998 & 56.531 & 67.964 & 67.934 & 66.787 & 65.882 \\
\hline \multicolumn{7}{|c|}{ Prediction of $f e_{j, t}$ when $f e_{j, t-1}$ is a leverage point (winsorizing) $(k=3)-N=3,315$} \\
\hline RMSE & 5.555 & 5.668 & 5.764 & 5.723 & 5.761 & 5.628 \\
\hline MAFE & 1.447 & 1.594 & 1.417 & 1.414 & 1.420 & 1.448 \\
\hline $\operatorname{SR}(\%)$ & 68.084 & 57.195 & 67.632 & 67.572 & 66.787 & 65.882 \\
\hline
\end{tabular}




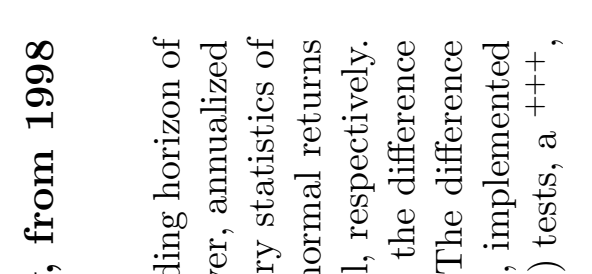

兽

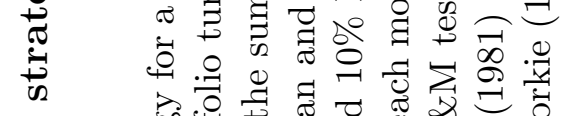

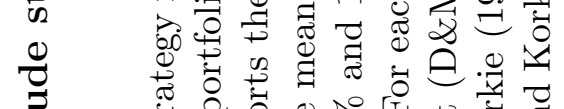

亦

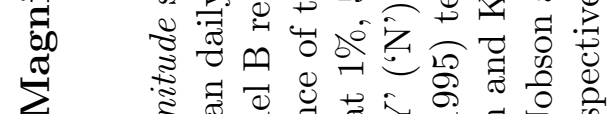

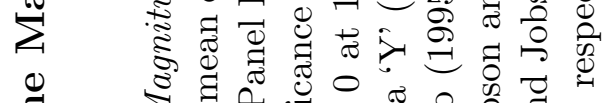

要

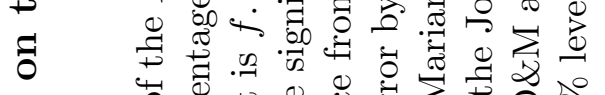

₹ c5n

的

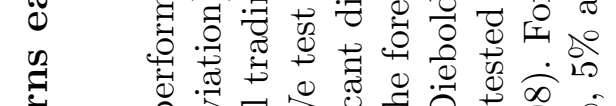

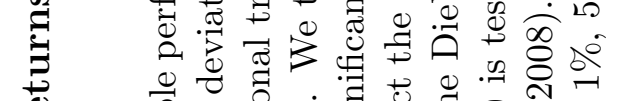

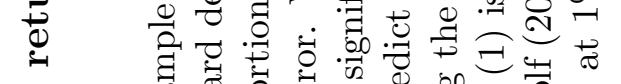

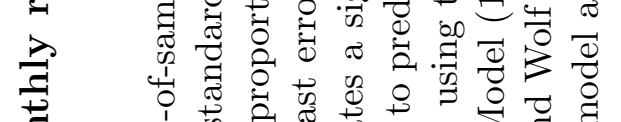

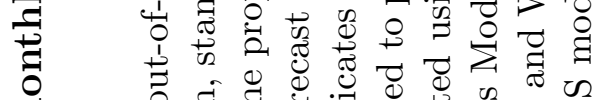

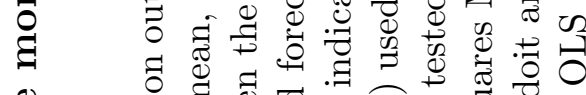

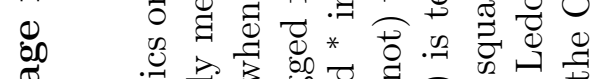

(1)

(

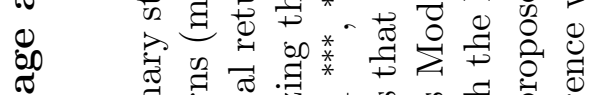

政

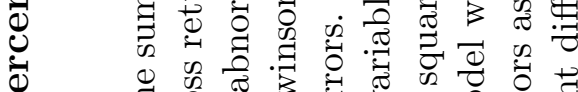

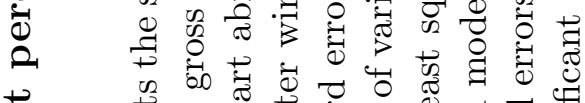

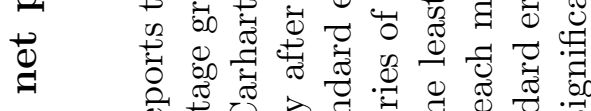

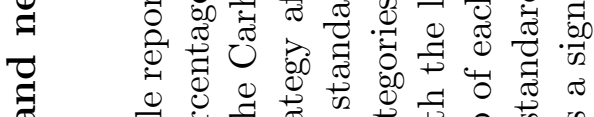

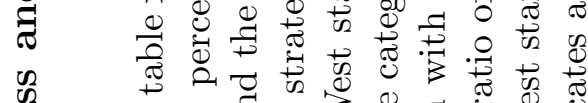

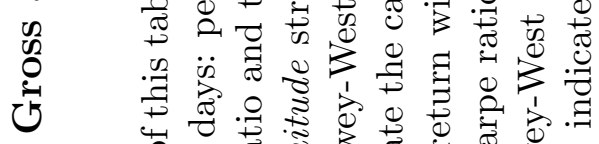

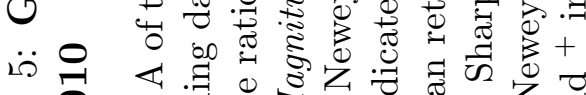

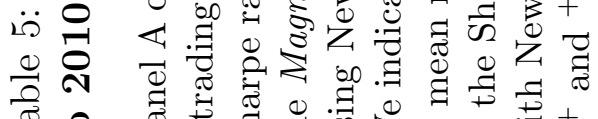

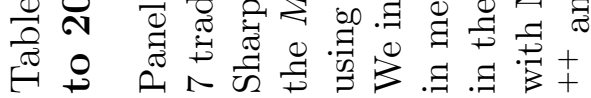

|

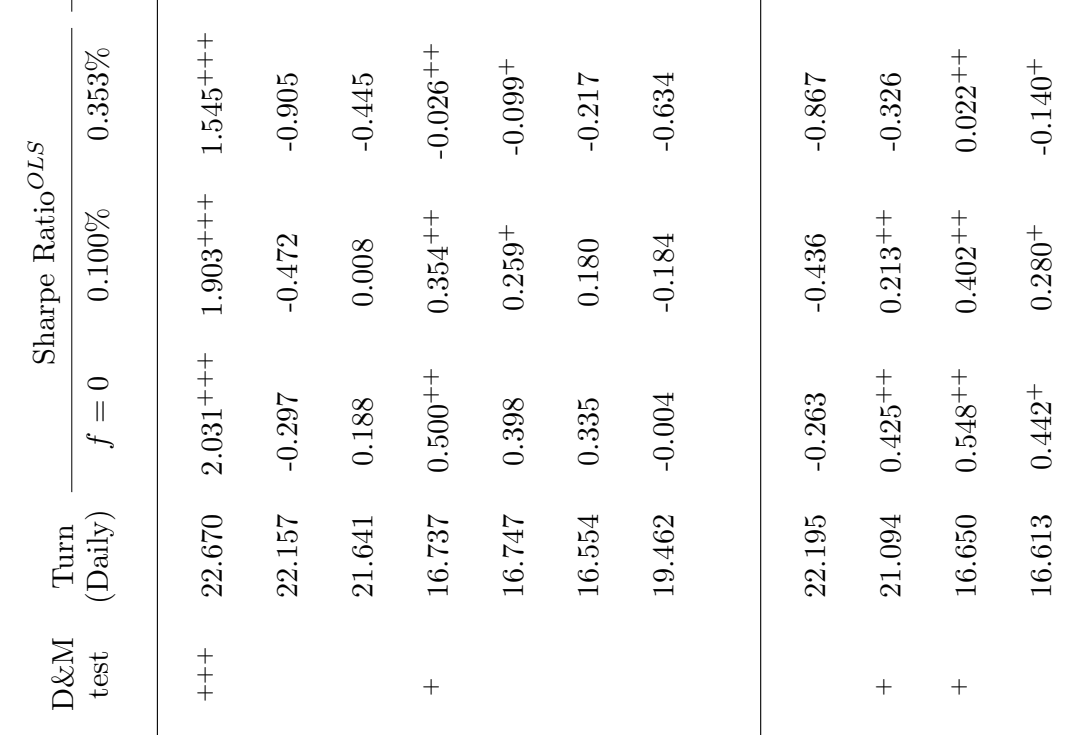

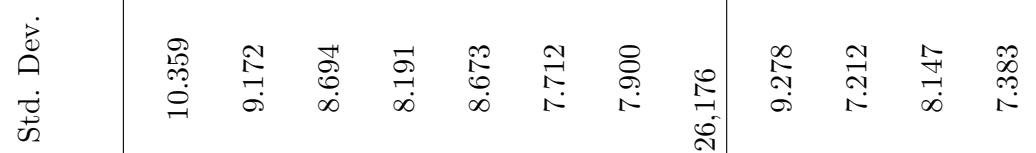

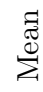

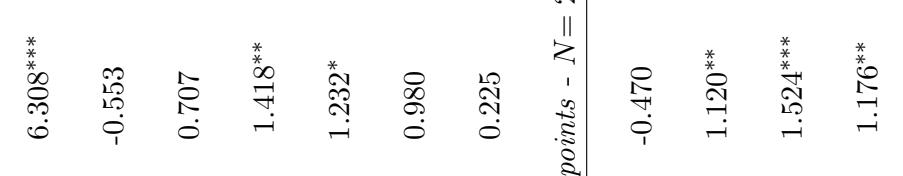

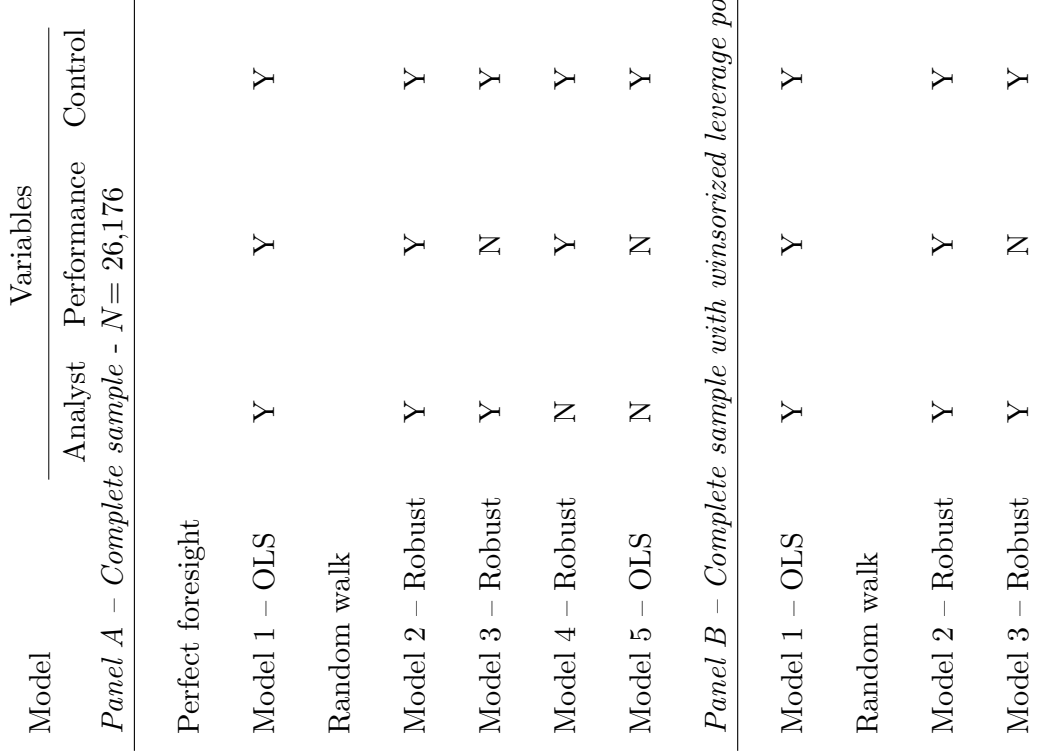




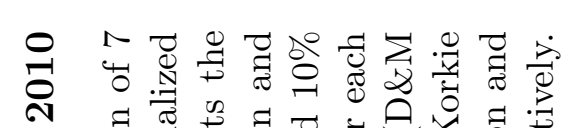

a

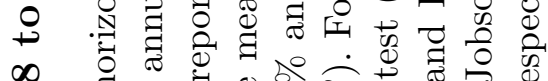

密

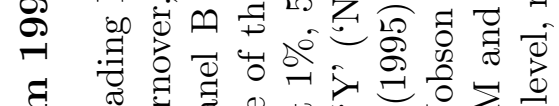

홍

a

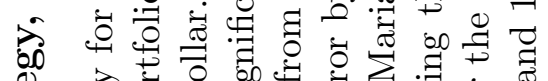

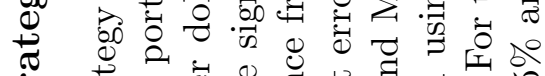

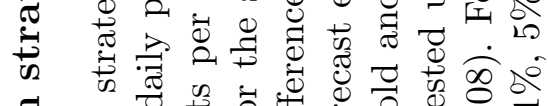

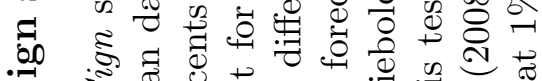

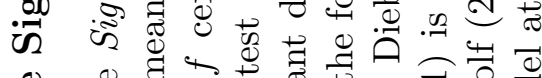

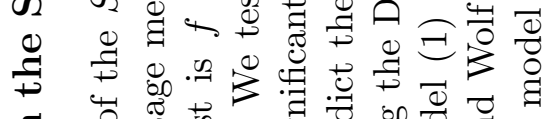

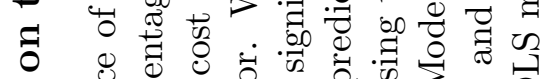

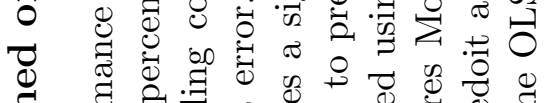

等

일

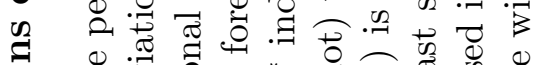

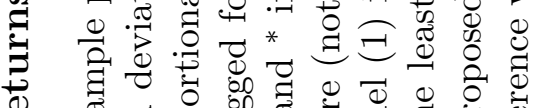

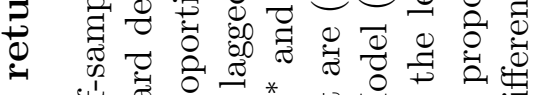

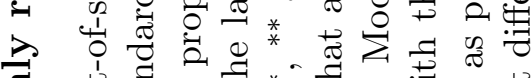

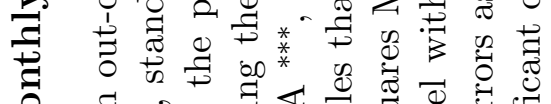

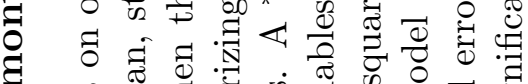

品

늘

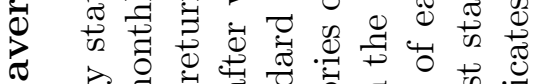

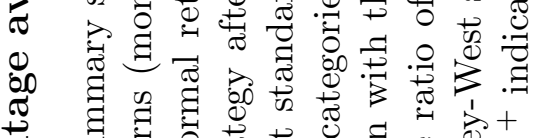

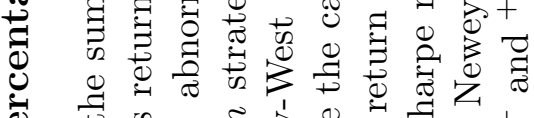

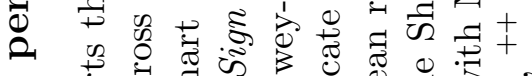

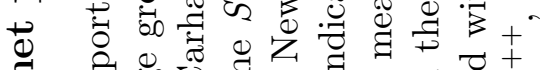

늘

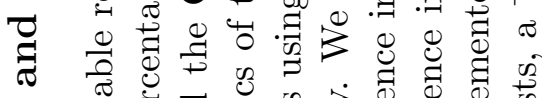

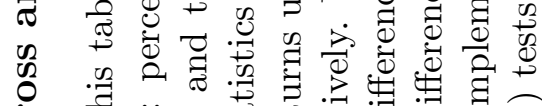

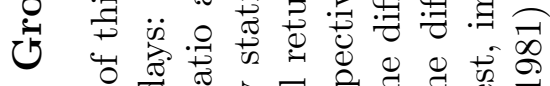

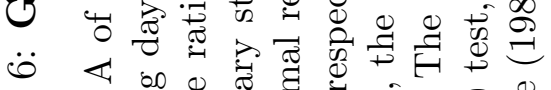

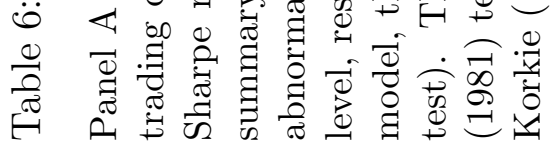

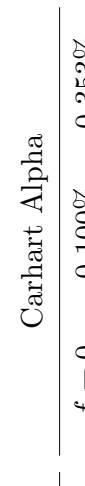

(2)

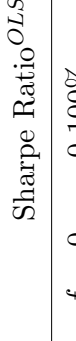

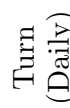

$\sum_{\substack{3 \\ 0}}$

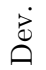

㔄

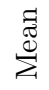

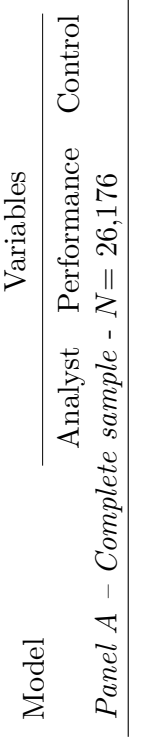

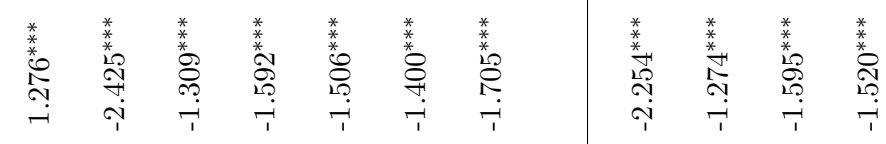

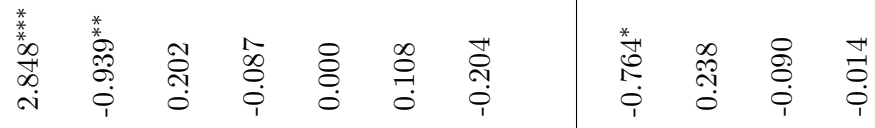

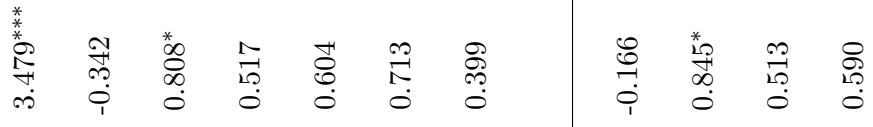

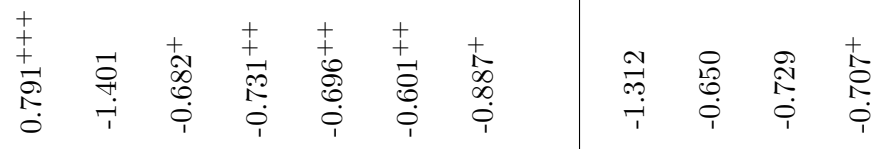

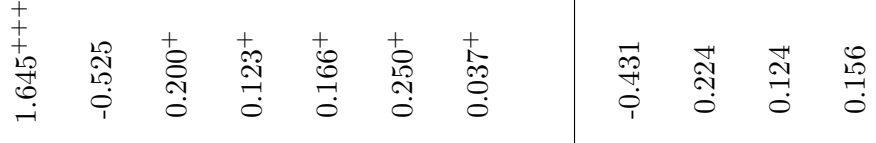

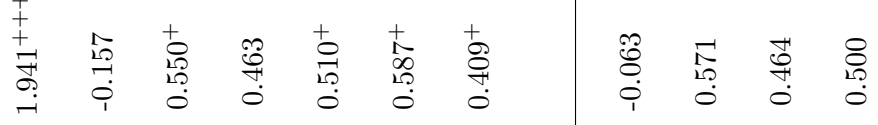

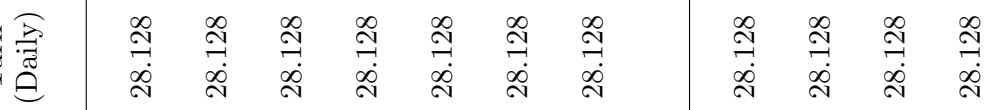

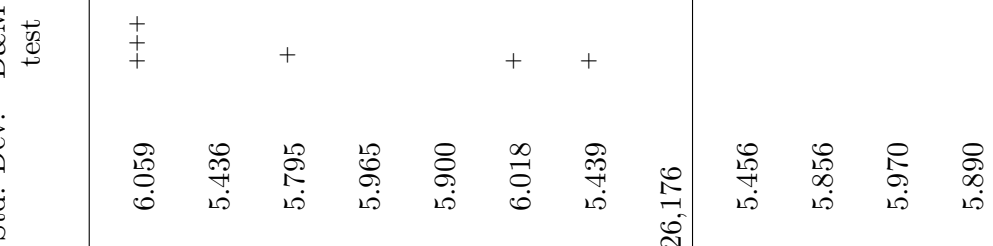

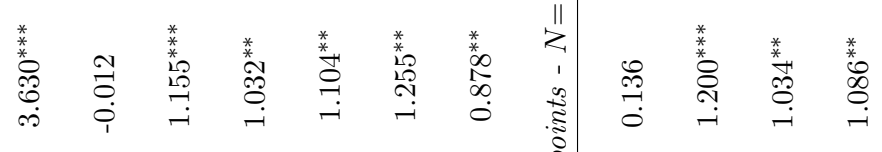

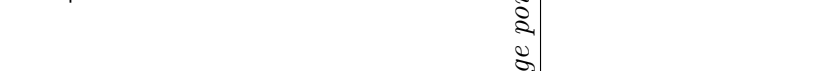
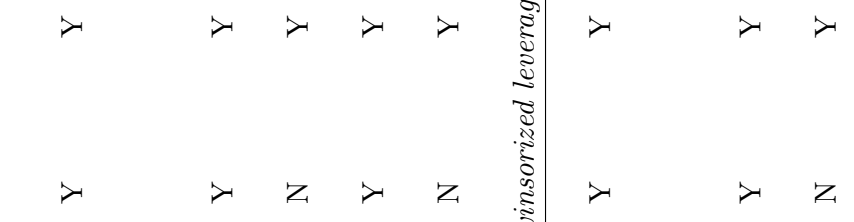

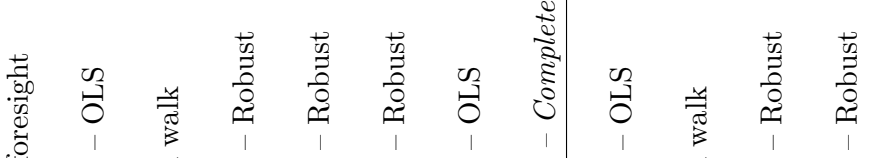

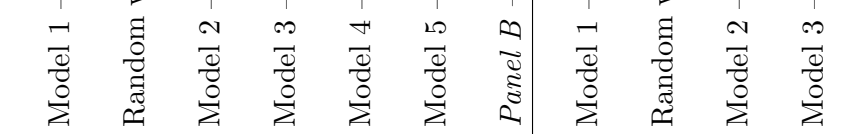




\section{Appendix: Summary of studies on the prediction of analysts' forecast \\ error}

Author

Period Prediction horizon $\left[t_{0}^{f}, t_{1}^{f}\right] \quad$ Investment horizon $\left[t_{0}, t_{1}\right]$

$\begin{array}{llll}\text { Dowen and W. Bauman (1995) } & \text { 1984-1988 } & \text { One-year-horizon } & \text { One-year-horizon } \\ & \mathrm{I} / \mathrm{B} / \mathrm{E} / \mathrm{S} & t_{0}^{f} \text { : April } 30^{t h} \text { of each year } & t_{0} \text { : May } 1^{\text {st }} \text { of each year } \\ & \text { Annual } & t_{1}^{f} \text { : Annual earnings } & t_{1}: t_{0}+12 \text { months }\end{array}$

Main finding: Analysts fail to use all of the information in published financial statements. Yet, it is not possible to earn abnormal returns based on that information.

Frankel and Lee (1998)

$\begin{array}{lll}\text { 1975-1993 } & \text { Three-year-horizon } & \text { From } 1 \text { to } 36 \text { months } \\ \text { I/B/E/S } & t_{0}^{f}: \text { June } 30^{\text {th }} \text { of each year } & t_{0}: \text { July } 1^{\text {st }} \text { of each year } \\ \text { Annual } & t_{1}^{f} \text { : Annual earnings } & t_{1}: t_{0}+1 \text { to } 36 \text { months }\end{array}$

Main finding: A strategy of buying (selling) firms with most pessimistic (optimistic) threeyear-ahead forecast error yields:

- mixed evidence of one-year ahead return predictability

- statistically significant abnormal returns over a three-year horizon.

\section{Hughes et al. (2008)}

Wieland (2011)

$$
\begin{array}{lll}
\text { 1984-2006 } & \text { One-year-horizon } & 4 \text { and } 13 \text { months } \\
\text { I/B/E/S } & t_{0}^{f}: \text { Annual earnings }+1 \text { month } & t_{0}: \text { Annual earnings }+1 \text { month } \\
\text { Annual } & t_{1}^{f}: \text { Next annual earnings } & t_{1}: t_{0}+4 \text { or } 13 \text { months }
\end{array}
$$

Main finding: Investment strategies aimed at exploiting the predictable component do not generate abnormal returns. Market prices reflect the predictable component of analyst errors.

1991-2005 One-year-horizon

$\mathrm{I} / \mathrm{B} / \mathrm{E} / \mathrm{S} \quad t_{0}^{f}$ : March $31^{\text {th }}$ of each year

Annual $t_{1}^{f}$ : Annual earnings

One-year-horizon

$t_{0}$ : April $1^{\text {st }}$ of each year

$t_{1}: t_{0}+12$ months

Main finding: A model based on analyst \& firm characteristics and fundamental signals can distinguish between forecasted earnings increases that do (vs do not) materialize and a trading strategy based on this prediction yields an average annual gross abnormal return of $14.1 \%$.
This paper
1995-2010 Five trading days

$\mathrm{I} / \mathrm{B} / \mathrm{E} / \mathrm{S} \quad t_{0}^{f}$ : Five trading days before

Quarterly quarterly earnings

$t_{1}^{f}$ : Quarterly earnings

\author{
Seven trading days \\ $t_{0}$ : 5 trading days before quarterly \\ earnings \\ $t_{1}$ : 2 trading days after quarterly \\ earnings
}

Main finding: A strategy of taking a long (short) position in stocks with the most pessimistic (optimistic) consensus forecast and closing the position on the day after the announcement has an annual gross abnormal return of $16.56 \%$. The trading strategies using least squares regression and/or focussing merely on the sign of the forecast error are not profitable. 